\title{
Detailed measurements of velocities and suspended sand concentrations over full-scale ripples in regular oscillatory flow
}

\author{
J. J. van der Werf, ${ }^{1}$ J. S. Doucette, ${ }^{2}$ T. O’Donoghue, ${ }^{2}$ and J. S. Ribberink ${ }^{1}$ \\ Received 23 June 2006; revised 19 October 2006; accepted 8 December 2006; published 9 May 2007.
}

[1] The knowledge and modeling of wave-induced sand transport over rippled beds still has significant shortcomings, which is partly related to a lack of measurements of the detailed processes from controlled laboratory experiments. We have carried out new measurements of the detailed time-dependent velocity and suspended sand concentration field around vortex ripples for regular oscillatory flow conditions. The fact that the ripples were mobile and the flow conditions were full-scale makes these measurements unique. We made velocity measurements for 14 different flows and concentration measurements for three of these flows. The velocity and concentration field above ripples are dominated by the generation and ejection of vortices on the ripple flanks around the time of flow reversal. Vortex formation results in near-ripple flow reversals ahead of free-stream reversals and velocity maxima near the ripple crest that are much higher than the free-stream maxima. Asymmetry in the free stream produces steady circulation cells with dominant offshore mean flow up the ripple lee slope, balanced by weaker onshore streaming up the ripple stoss slope as well as higher up in the flow. The timeand bed-averaged horizontal velocity profile comprises an offshore streaming near the bed and an onshore drift higher up in the flow. The vortices are responsible for three main concentration peaks: one just after on-offshore flow reversal associated with the passage of a sand-laden vortex followed by two smaller peaks due to advected suspension clouds generated by vortex action at the neighboring onshore ripples. The sand flux field measured for one typical asymmetric flow condition is dominated by an offshore flux associated with the suspended sand cloud generated by vortex shedding from the ripple's lee slope around the time of on-offshore flow reversal. The net (time-averaged) currentrelated and wave-related horizontal sand fluxes are generally offshore directed and mostly contained within 1.5 ripple heights above the ripple crest. The wave-related suspended transport component is larger, but the contribution of the current-related suspended sand transport cannot be neglected. In addition to the measured offshore net transport of suspended sand, there is an onshore-directed transport very close to the ripple surface. The total net transport is in the offshore direction for this specific asymmetric flow condition.

Citation: van der Werf, J. J., J. S. Doucette, T. O’Donoghue, and J. S. Ribberink (2007), Detailed measurements of velocities and suspended sand concentrations over full-scale ripples in regular oscillatory flow, J. Geophys. Res., 112, F02012, doi:10.1029/2006JF000614.

\section{Introduction}

[2] Knowledge of sand transport processes induced by waves and currents is of crucial importance in order to understand the morphological behavior of the coastal system and to be able to predict future changes as a result of natural processes and human interferences. One of the largest knowledge gaps in sand transport processes is in the understanding of wave-induced sand transport over ripples,

\footnotetext{
${ }^{1}$ Water Engineering and Management, University of Twente, Enschede, Netherlands.

${ }^{2}$ Department of Engineering, King's College, University of Aberdeen, Aberdeen, UK.

Copyright 2007 by the American Geophysical Union. 0148-0227/07/2006JF000614\$09.00
}

typically $0.01-0.1 \mathrm{~m}$ high and $0.1-1.0 \mathrm{~m}$ long. This is reflected in the inability of models to accurately predict the net transport rate under these conditions. An intercomparison of different transport models and a comparison of model predictions with field and laboratory data by Davies et al. [1997] and Davies et al. [2002] have shown that the current-related transport is generally well predicted for rippled bed conditions but agreement is poor for the wave-related transport component.

[3] Above rippled beds, momentum transfer and the associated sand dynamics in the near-bed layer are dominated by coherent motions, specifically by the process of vortex formation above ripple slopes and the shedding of these vortices around flow reversal. Above steep longcrested ripples, this well-organized vortex process is highly effective in entraining sand into suspension. In a near-bed 
layer with a thickness of one to two times the ripple height, the flow dynamics are dominated by these coherent periodic vortex structures, whereas above this layer the coherent motions break down and are replaced by random turbulence [Davies and Villaret, 1997]. The phase of sand pick-up from the bed during the wave cycle is linked to the phase of vortex shedding. This has potentially important consequences for the net sand transport rate beneath asymmetrical waves which can be negative ("offshore") despite higher positive ("onshore") orbital velocities. The underlying mechanism of this wave-related transport opposing the direction of wave propagation in the case of asymmetrical waves is the existence of phase differences between the peak concentrations and peak velocities related to the generation of vortices on the lee side of steep ripples. Because of the time needed for sand settling, phase lags are generally more important for finer sand and shorter wave periods.

[4] Process-based sand transport models [e.g., Hansen et al., 1994; Andersen, 1999; Malarkey and Davies, 2002; Eidsvik, 2004; Davies and Thorne, 2005] represent many of the detailed physical processes involved in sand transport by waves over rippled beds. These unsteady models have rarely been validated against data from experiments with full-scale, mobile ripples [see van der Werf, 2006]. In order to further develop such models and to increase our understanding of the complex nature of ripple regime sand transport, detailed measurements of the velocity and sand concentration field above rippled beds from controlled, fullscale laboratory experiments are required.

[5] Many laboratory measurements of velocity and concentration have been made over rippled beds in the past but these were generally limited either by the capability of the available instrumentation or by the experimental scale or setup. For example, many experiments have been carried out to measure velocities over ripples in which the rippled bed was fixed. In some cases [e.g., Sato, 1987; Doering and Baryla, 2002] the velocities were measured using a laser Doppler anemometer (LDA) or an acoustic Doppler velocity meter (ADV), which provide velocity measurements at selected points only. In other cases [e.g., Earnshaw and Greated, 1998; Marin, 2004] the full flow field was measured using particle image velocimetry (PIV). Detailed velocity measurements over mobile ripples are rare and only Ahmed and Sato [2001] have measured the full flow field over mobile ripples using PIV. However, the flow period $T$ was short and the ripples were small in their experiments $(T=3 \mathrm{~s}$, ripple height $\eta=0.02 \mathrm{~m}$, ripple length $\lambda=0.16 \mathrm{~m})$ compared with full-scale conditions.

[6] Bosman [1982] used an optical concentration meter (OPCON) to perform point concentration measurements over ripples. However, also in his experiments flow periods were short $(T<3 \mathrm{~s})$ and ripples were small compared to fullscale conditions. Point measurements of concentration for full-scale ripples have been obtained by Clubb [2001] using transverse suction sampling in an oscillatory flow tunnel. Villard et al. [2000], Vincent and Hanes [2002] and Thorne et al. [2003] performed acoustic backscatter system (ABS) measurements of time-dependent concentrations in large wave flumes. However, in each of these studies no corresponding detailed velocity measurements were made. Chen [1992] carried out point measurements of both velocities and concentrations, but these were small-scale experiments with short wave periods $(T=1.76 \mathrm{~s})$ and small ripples.

[7] A new experimental study was carried out in the Aberdeen oscillatory flow tunnel (AOFT) at the University of Aberdeen to provide a complete set of detailed measurements of velocities and concentrations over rippled beds. In this facility oscillatory flow corresponding to the near-bed flow induced by moderate (nonbreaking) waves can be simulated at full scale for a wide range of relevant coastal conditions. The objective of the experiments was to obtain measurements of the combined time-dependent flow and suspended sand concentration field above full-scale rippled beds under controlled regular flow conditions, and to increase our understanding of the essential physical processes involved. These new measurements distinguish themselves from previous work by the fact that they involve "natural", mobile ripples generated by oscillatory flows with field-scale periods and amplitudes, and that both velocity and concentration measurements were carried out.

[8] In this paper the new measurements of the detailed time-dependent sand transport processes over rippled beds are presented and discussed. A description of the experimental facility, measuring methods and experimental conditions is given in Section 2. The next section discusses the time-dependent velocity, concentration and sand flux measurements. More specifically, we look into the near-bed flow along the ripple and the timing of the concentration peaks, since these are important in the context of sand transport. The time-averaged behavior of the sand transport processes above rippled beds is described in Section 4. The conclusions are presented in the final section.

\section{Experimental Setup}

\subsection{Experimental Facility}

[9] The Aberdeen oscillatory flow tunnel (AOFT) is a large laboratory facility in which near-bed horizontal flows, equivalent in period and amplitude to the near-bed flows of full-scale waves, can be generated over sand beds. Oscillatory flow tunnels such as the AOFT have a closed top and therefore do not simulate wave effects associated with the free water surface (e.g., vertical orbital motions). The AOFT has an overall length of $16 \mathrm{~m}$ with a $10 \mathrm{~m}$ long, glass-sided rectangular test section, $0.75 \mathrm{~m}$ high and $0.3 \mathrm{~m}$ wide. The test section was filled with a $0.25 \mathrm{~m}$ thick sand bed leaving $0.5 \mathrm{~m}$ for the flow. A more detailed description of the facility can be found in O'Donoghue and Clubb [2001].

[10] Each experiment started with a flat bed and the ripples were allowed to develop over time until they reached "equilibrium", i.e., when the average ripple height, length and shape remained more or less constant in time. Measurements were then made of the ripple dimensions, time-dependent velocity field, time-dependent sand concentrations, time-averaged sand concentrations and net sand transport rates.

\subsection{Ripple Dimensions Measurement}

[11] Ripple dimensions were measured using a laser displacement sensor (LDS) mounted on a positioning carriage. The LDS made point measurements of bed elevation with a $0.05 \mathrm{~mm}$ resolution in the vertical direction. The laser 
displacement system was used to measure the equilibrium rippled bed. Six parallel profiles were measured, spaced at $40 \mathrm{~mm}$ intervals across the tunnel width, with heights measured every $5 \mathrm{~mm}$ along each profile.

[12] For LDS measurements the flow is stopped. To measure the ripples while the flow is active, an acoustic sand ripple profiler (SRP) was used. The SRP uses a sweeping sonar beam to measure $1.6 \mathrm{~m}$ long profiles of the bed with an accuracy of $\pm 5 \mathrm{~mm}$ in the vertical direction; each sonar scan of the bed takes $35 \mathrm{~s}$ approximately. Further details on the SRP can be found in Doucette and O’Donoghue [2006].

\subsection{Velocity Measurement}

[13] Flow velocities over the ripples were measured using a cross-correlation particle image velocimetry (PIV) system. $\mathrm{PIV}$ is a planar measurement technique wherein a pulsed laser light sheet is used to illuminate a flow field seeded with tracer particles small enough to accurately follow the flow. For the present experiments, the flow is illuminated from above using a double pulse Yag laser with a pulse separation of $2 \mathrm{~ms}$. The positions of the particles are recorded on a cross-correlation camera with a resolution of $1000 \times 1000$ pixels mounted outside the tunnel perpendicular to the flow. The camera and laser are synchronized and the camera grabs a pair of images at a rate of approximately $13.2 \mathrm{~Hz}$. The data processing consists of determining the average displacement of the particles over a small interrogation region in the image. Knowledge of the time interval between the light sheet pulses then permits computation of the flow velocity. For the present experiments, measurements were made using two camera viewing areas of $0.40 \times 0.40 \mathrm{~m}$ and $0.235 \times 0.235 \mathrm{~m}$. The crosscorrelation analysis between each image pair was carried out with interrogation areas of $32 \times 32$ pixels and an overlap of 16 pixels. The spatial resolution of the resulting velocity field measurement is $6.4 \times 6.4 \mathrm{~mm}$ and $3.8 \times 3.8 \mathrm{~mm}$ for the $0.40 \times 0.40 \mathrm{~m}$ and $0.235 \times 0.235 \mathrm{~m}$ viewing areas respectively; the corresponding velocity resolution is $20 \mathrm{~mm} / \mathrm{s}$ and $12 \mathrm{~mm} / \mathrm{s}$.

[14] The suspended sand acted as the seeding agent, and therefore measured velocities are velocities of the suspended sand rather than the water itself. The grain size distribution of the suspended sand was measured by taking suction samples at elevations between 10 and $120 \mathrm{~mm}$ above the ripple crest level: median grain sizes were found to range from 0.29 to $0.37 \mathrm{~mm}$. The corresponding fall velocities computed using the formula of Van Rijn [1993] are of the order of $0.04-0.05 \mathrm{~m} / \mathrm{s}$. This gives an indication of the difference between the measured vertical velocity component measured and the actual water velocity.

[15] Many of the experiments involved asymmetric oscillatory flow with higher "onshore" than "offshore" velocities. Because of the asymmetry, the ripples migrate onshore during the experiment and may change shape slightly as they migrate. In order to limit the effects of migration and distortion on ensemble-averaged results, the duration of the PIV measurements was limited to approximately five flow cycles in each experiment. Depending on the flow period, this corresponds to between approximately 200 and 500 image pairs recorded for each experiment.

\subsection{Suspended Sand Concentration Measurement}

[16] Vertical profiles and point measurements of the timedependent suspended sand concentration were measured using an acoustic backscatter system (ABS) and an optical concentration meter (OPCON) respectively. A transverse suction system (TSS) was used to measure the vertical profiles of time-averaged concentration. Since two of these systems are intrusive within the flow field, the measurement of suspended sand concentration was performed separately from the PIV measurements. The concentration and velocity measurements could still be combined to produce sand flux values since the flow conditions and resulting ripple size and shape were repeatable between the experiments. The consistency between experiments of the equilibrium ripple size and shape for a given flow condition has been shown by Doucette and O'Donoghue [2006]. This consistent size and shape was maintained as the ripples migrated.

[17] An acoustic backscatter system (ABS) was deployed to measure time-dependent suspended sand concentrations. The ABS used was a three-frequency AquaScat unit, operating at $0.98,2.52$ and $4.8 \mathrm{MHz}$. These three transducers were aligned across the tunnel. Only ABS concentration measurements from the middle frequency transducer are presented here since the low-frequency transducer had too wide a footprint while the higher-frequency transducer had problems with attenuation.

[18] The ABS transducers were mounted into the tunnel lid with their heads flush with the underside of the lid at $0.5 \mathrm{~m}$ above the flat sand bed and looking vertically downward. The ABS data are averaged online to give backscatter profiles measured at $8 \mathrm{~Hz}$ and these are subsequently converted to high-resolution concentration profiles. The averaging is required, because of the statistical nature of the backscattered signal. The system provides concentration profiles with a $0.005 \mathrm{~m}$ vertical spatial resolution extending between 0.1 to $0.6 \mathrm{~m}$ below the transducers. Calibration was based on concentrations measured by the OPCON and TSS.

[19] The ABS measured continuously while six entire equilibrium ripples migrated underneath it. The bed level below the ABS was continuously monitored by the SRP. The ABS concentration measurements are accurate within approximately a factor of 2 (because of uncertainties in the suspended sand grain size) with an uncertainty in the vertical position of $\pm 5 \mathrm{~mm}$.

[20] Point measurements of time-dependent concentrations were made with an optical concentration meter $(\mathrm{OPCON})$, which can measure concentrations in the range of $0.1-40 \mathrm{~g} / \mathrm{l}$. The measurement method is based on the extinction of near-infrared radiation by suspended particles applying Beer's law. The OPCON consists of a transmitter and a receiver, spaced $30 \mathrm{~mm}$ apart with dimensions of $2.6 \times 2.6 \mathrm{~mm}$, and a measuring volume of $2.6 \times 2.6 \times$ $30 \mathrm{~mm}$. The orientation of the light beam between transmitter and receiver is horizontal and perpendicular to the flow. The temporal resolution of the OPCON measurements is $50 \mathrm{~Hz}$. For the present experiments, the OPCON was calibrated in a stirring vessel with known concentrations for five different sand mixtures to determine the influence of the grain size on the calibration coefficient.

[21] Since the OPCON is only capable of point measurements and was difficult to move horizontally in the water 
tight flow tunnel, the migration of the ripples themselves was used to facilitate measurements along the ripple length. For each flow condition, the OPCON was positioned at a fixed elevation above the ripple crest level. Measurements of suspended sand concentration were then recorded as the ripple migrated past the sensor. Once a whole ripple had migrated past, the OPCON was raised to a new measurement level and the observations recorded as another ripple migrated past. These measurements were repeated at five different elevations. The estimated total (random) error in the OPCON measured concentration is $20 \%$, and the uncertainty in vertical position with respect to the ripple surface is $\pm 5 \mathrm{~mm}$. This estimation does not include uncertainties associated with the ripple size and shape.

[22] A transverse suction system (TSS) was used to measure time-averaged concentration profiles of suspended sand. The system consists of 6-8 separate horizontal intake nozzles, each with an inner diameter of $3 \mathrm{~mm}$, which were positioned perpendicular to the flow. The nozzles were mounted at the same elevation in a line covering the full ripple length and spaced 35 or $70 \mathrm{~mm}$ apart. The duration of suction sampling was $200 \mathrm{~s}$ corresponding to 40 flow cycles for flows with a period of $5 \mathrm{~s}$ and resulting in approximately 51 of sample for each nozzle. The time-averaged suspended sand concentration was determined by drying and weighing the sampled water-sand mixture. The particle size distribution of the dried sample was determined by sieve analysis and the calibration of the suction efficiency was determined by the method outlined in Bosman et al. [1987]. The estimated total (random) error in the measured concentration is $5 \%$, and the uncertainty in vertical position with respect to the ripple surface $\pm 4 \mathrm{~mm}$. This estimation does not include uncertainties associated with the ripple size and shape.

[23] Suspended sand samples were collected with the TSS once equilibrium ripples were established for the given flow condition. All nozzles of the TSS were mounted at the same elevation relative to a flat bed. Once the samples were collected, all the nozzles were moved to a higher position above the ripple and sampling was repeated at a total of five different elevations. Since the sampling took $200 \mathrm{~s}$ to complete, the horizontal position of the nozzles had to be corrected for migration of the ripple between sampling. Nozzles were also repositioned horizontally during the suction sampling if the ripple migrated more than $0.02 \mathrm{~m}$. This was accomplished by switching off both the AOFT piston and the TSS in order to reposition the nozzles horizontally before continuing with the sampling. The actual height of each nozzle above the rippled bed was recorded before and after suction sampling by lowering the sampler to the bed from the set elevation (in still water). Elevation of the nozzle above the rippled bed was taken as an average of these two heights to account for the changes due to ripple migration during the sampling.

\subsection{Net Sand Transport Measurement}

[24] The net sand transport rates were measured using a mass conservation technique. After the ripples reached equilibrium, the bed profile over the full test section was measured using LDS and all sand was removed from the sand traps. The flow was run again for 180 cycles for Mr5b63 and Mr5c63, and 720 cycles for Mr5a63. Then the bed profile over the full test section was measured again and the sand taken from the ends was dried and weighed. Given the sand masses in the traps at both ends of the test section and the volume changes derived from the bed profiling system, the net sand transport rates along the test section were calculated by integration of the sand continuity equation from the left-hand and the right-hand side boundary. The calculated net transport rate in (or close to) the middle of the test section was taken as a representative value. Errors involved in net transport measurements are due to uncertainty in the value of the bed porosity and possible change in porosity during the experiment. Repeated measurements for the same condition show that the (random) error in the measured net transport rate is $\approx 20 \%$.

\subsection{Experimental Conditions}

[25] The experimental conditions are listed in Table 1. The table includes the measured equilibrium ripple height, $\eta$, ripple length, $\lambda$, ripple steepness, $\eta / \lambda$, ripple migration rate, $c_{\mathrm{r}}$, and net sand transport rate $\left\langle q_{\mathrm{s}}\right\rangle$ for each experiment. The analyses below focus on the experiments denoted with an asterisk. Note that mobility number and ripple size vary considerably over the range of experiments. The sand used for the experiments was well sorted with $D_{10}, D_{30}, D_{50}, D_{70}$ and $D_{90}$ equal to $0.25 \mathrm{~mm}, 0.35 \mathrm{~mm}, 0.44 \mathrm{~mm}, 0.53 \mathrm{~mm}$ and $0.66 \mathrm{~mm}$ respectively. Ripple dimensions and flow velocities were measured for all of the experiments; concentrations and net sand transport rates were only measured for experiments Mr5a63, Mr5b63 and Mr5c63.

[26] The velocity function for the regular flow experiments had the same form as the near-bed flow beneath Stokes second-order waves:

$$
u(t)=u_{1} \cos (\omega t)+u_{2} \cos (2 \omega t)
$$

where $u_{1}$ and $u_{2}$ are the first- and second-order near-bed orbital velocity amplitude respectively, and $\omega=2 \pi / T$ is angular frequency where $T$ is the flow period. The velocity values presented in Table 1 are based on the ripple-averaged velocity measured at approximately three ripple heights above the ripple crest level.

[27] The following equations are used to compute the parameters:

Root-mean-square orbital velocity $u_{\mathrm{rms}}=\sqrt{0.5 u_{1}^{2}+0.5 u_{2}^{2}}$

Orbital diameter

$$
d_{\mathrm{o}}=\frac{\sqrt{2} u_{\mathrm{rms}} T}{\pi}
$$

Degree of flow asymmetry

$$
R=\frac{u_{1}+u_{2}}{2 u_{1}}
$$

$$
\text { Mobility number } \quad \psi=\frac{2 u_{\mathrm{rms}}^{2}}{\Delta g D_{50}}
$$

where $\Delta=\left(\rho_{\mathrm{s}}-\rho_{\mathrm{w}}\right) / \rho_{\mathrm{w}}=1.65$ is the relative sand density with $\rho_{\mathrm{w}}$ the water density and $\rho_{\mathrm{s}}$ the sand density. 
Table 1. Experimental Conditions and Measured Ripple Height $\eta$, Ripple Length $\lambda$, Ripple Steepness $\eta / \lambda$, Ripple Migration Rate $c_{\mathrm{r}}$, and Net Sand Transport Rate $\left\langle q_{\mathrm{s}}\right\rangle^{\mathrm{a}}$

\begin{tabular}{|c|c|c|c|c|c|c|c|c|c|c|c|c|c|}
\hline Experiment & $D_{50}, \mathrm{~mm}$ & $T, \mathrm{~s}$ & $u_{1}, \mathrm{~m} / \mathrm{s}$ & $u_{2}, \mathrm{~m} / \mathrm{s}$ & $u_{\mathrm{rms}}, \mathrm{m} / \mathrm{s}$ & $d_{\mathrm{o}}, \mathrm{m}$ & $R$ & $\psi$ & $\eta, \mathrm{m}$ & $\lambda, \mathrm{m}$ & $\eta / \lambda$ & $c_{\mathrm{r}}, \mathrm{mm} / \mathrm{min}$ & $\left\langle q_{\mathrm{s}}\right\rangle, 10^{-6} \mathrm{~m}^{2} / \mathrm{s}$ \\
\hline Mr5a54 & 0.44 & 5.0 & 0.31 & 0.023 & 0.22 & 0.49 & 0.54 & 14 & 0.065 & 0.29 & 0.22 & $\ldots$ & $\ldots$ \\
\hline Mr5a58 & 0.44 & 5.0 & 0.32 & 0.044 & 0.23 & 0.51 & 0.57 & 15 & 0.045 & 0.25 & 0.18 & $\ldots$ & $\ldots$ \\
\hline Mr5a63* & 0.44 & 5.0 & 0.31 & 0.057 & 0.22 & 0.50 & 0.59 & 14 & 0.039 & 0.24 & 0.16 & $5-7$ & 0.43 \\
\hline $\operatorname{Mr} 5 \mathrm{~b} 50 *$ & 0.44 & 5.0 & 0.48 & 0.000 & 0.34 & 0.76 & 0.50 & 32 & 0.080 & 0.46 & 0.17 & $\ldots$ & $\ldots$ \\
\hline $\operatorname{Mr} 5 \mathrm{~b} 54^{*}$ & 0.44 & 5.0 & 0.56 & 0.025 & 0.40 & 0.89 & 0.52 & 44 & 0.070 & 0.41 & 0.17 & $\ldots$ & $\ldots$ \\
\hline Mr5b58* & 0.44 & 5.0 & 0.53 & 0.065 & 0.38 & 0.85 & 0.56 & 40 & 0.070 & 0.41 & 0.17 & $\ldots$ & $\ldots$ \\
\hline Mr5b63* & 0.44 & 5.0 & 0.54 & 0.095 & 0.39 & 0.87 & 0.59 & 42 & 0.076 & 0.41 & 0.19 & 18 & -3.69 \\
\hline $\operatorname{Mr} 5 \mathrm{c} 63^{*}$ & 0.44 & 5.0 & 0.65 & 0.120 & 0.47 & 1.05 & 0.59 & 61 & 0.081 & 0.49 & 0.17 & $10-15$ & -14.0 \\
\hline $\operatorname{Mr} 5 \mathrm{~d} 54$ & 0.44 & 5.0 & 0.43 & 0.015 & 0.30 & 0.68 & 0.52 & 26 & 0.075 & 0.43 & 0.17 & $\ldots$ & $\ldots$ \\
\hline $\operatorname{Mr} 5 \mathrm{~d} 58$ & 0.44 & 5.0 & 0.43 & 0.044 & 0.31 & 0.69 & 0.55 & 26 & 0.050 & 0.35 & 0.14 & $\cdots$ & $\cdots$ \\
\hline Mr5d63 & 0.44 & 5.0 & 0.45 & 0.080 & 0.32 & 0.73 & 0.59 & 29 & 0.050 & 0.54 & 0.09 & $\ldots$ & $\ldots$ \\
\hline Mr363 & 0.44 & 3.1 & 0.34 & 0.060 & 0.24 & 0.34 & 0.59 & 17 & 0.025 & 0.19 & 0.14 & $\ldots$ & $\ldots$ \\
\hline Mr463 & 0.44 & 4.1 & 0.44 & 0.074 & 0.32 & 0.58 & 0.58 & 28 & 0.045 & 0.28 & 0.16 & $\ldots$ & $\ldots$ \\
\hline Mr763 & 0.44 & 7.4 & 0.52 & 0.070 & 0.37 & 1.24 & 0.57 & 39 & 0.100 & 0.55 & 0.18 & $\ldots$ & $\ldots$ \\
\hline
\end{tabular}

${ }^{\text {a }}$ The analyses focus on the experiments denoted with an asterisk.

Explanation of the nomenclature of the experiments: in experiment Mr5b63, "M" denotes medium sand, " $r$ " is regular oscillatory flow, " 5 " is the flow period, " $b$ " is an indication of the orbital velocity, and " 63 " denotes the imposed degree of flow asymmetry.

[28] In the following sections we look at the velocity and concentration fields for six particular experiments: Mr5a63, Mr5b50, Mr5b54, Mr5b58, Mr5b63, and Mr5c63. The general flow and concentration behavior is representative of the flow and concentration measured in the other experiments. The ripple geometries shown below the measured flow, suspended sand concentration and suspended sand flux field reflect the actual shape of ripple above which the measurements were carried out.

\section{Time-Dependent Behavior}

\subsection{Time-Dependent Flow Field}

[29] Figure 1 shows the measured velocity field corresponding to eight phases within the flow period for experiment Mr5b63. Figure 1, top, shows the free-stream orbital velocity $u_{\infty}$ and also shows the phases for which the eight velocity fields are presented. Note that the full measurement at each phase consists of 66 vertical profiles over the length of the ripple but that only 12 profiles are shown for clearer presentation. The velocities have been ensemble-averaged over four flow cycles.

[30] Positive, "onshore" flow is directed to the right. Horizontal and vertical axes, $x$ and $z$, have their origin at the ripple crest and are normalized by the ripple length $\lambda$ and ripple height $\eta$ respectively. The stoss slope of the ripple is the slope facing offshore (i.e., the left side of the ripple in Figure 1) and the lee slope is the slope facing onshore. The ripple lee slope is steeper than the stoss slope, giving the ripple an asymmetric shape that is consistent with the asymmetric flow.

[31] With reference to Figure $1(\mathrm{a}-\mathrm{h})$, the general flow behavior is as follows:

[32] 1. (a): Off-onshore flow reversal. Free-stream velocities are close to zero but there are higher near-bed onshore velocities on the stoss slope due to the ejection of the stoss vortex from the stoss side of the ripple.
[33] 2. (b): Free stream is accelerating onshore. The flow accelerates as it rises up the stoss slope because of the constriction of the flow from the trough to the crest. This produces high velocity flow over the ripple crest, extending to $z / \eta \approx 0.7$. Flow decelerates down the lee slope, producing very low near-bed velocities toward the ripple trough.

[34] 3. (c): Time of maximum onshore free-stream velocity. Flow acceleration over the ripple crest persists. There is strong separation in the lee of the ripple with flow starting to reverse near the bed on the lee slope.

[35] 4. (d): Onshore free-stream velocity is decelerating. The region of high velocity flow over the ripple crest is no longer present. Flow reversal has occurred at the bed in the lee resulting in a well-defined vortex.

[36] 5. (e): Free-stream velocity is close to on-offshore flow reversal. The free-stream velocity is weak and the lee vortex starts to move toward the ripple crest, producing relatively high, offshore-directed near-bed velocities on the lee slope. These near-bed velocities are much higher than at times of off-onshore flow reversal (Figure 1a), since the lee vortex is stronger than the stoss vortex because of flow asymmetry.

[37] 6. (f): Free stream is accelerating offshore. Freestream flow reversal has occurred and the free-stream velocity is low. However, offshore velocities at the ripple crest are already high, caused by the phase lead of the nearbed flow acceleration and the constriction of the flow from the trough to the crest. This jet flow is responsible for the ejection of the lee side vortices over the ripple crest. Note that the velocity magnitude at the crest at this time is as high as the maximum free-stream velocity.

[38] 7. (g): Close to time of maximum offshore freestream velocity. This is similar to $\mathrm{C}$, but the degree of flow separation on the ripple flank is less because of flow asymmetry.

[39] 8. (h): Offshore free-stream velocity is decelerating. The stoss slope vortex grows as the offshore flow decelerates. This vortex is much smaller than the corresponding vortex formed on the lee slope during onshore flow (Figure 1d).

[40] Figure 2 shows the measured velocity field corresponding to the same eight phases within the flow 

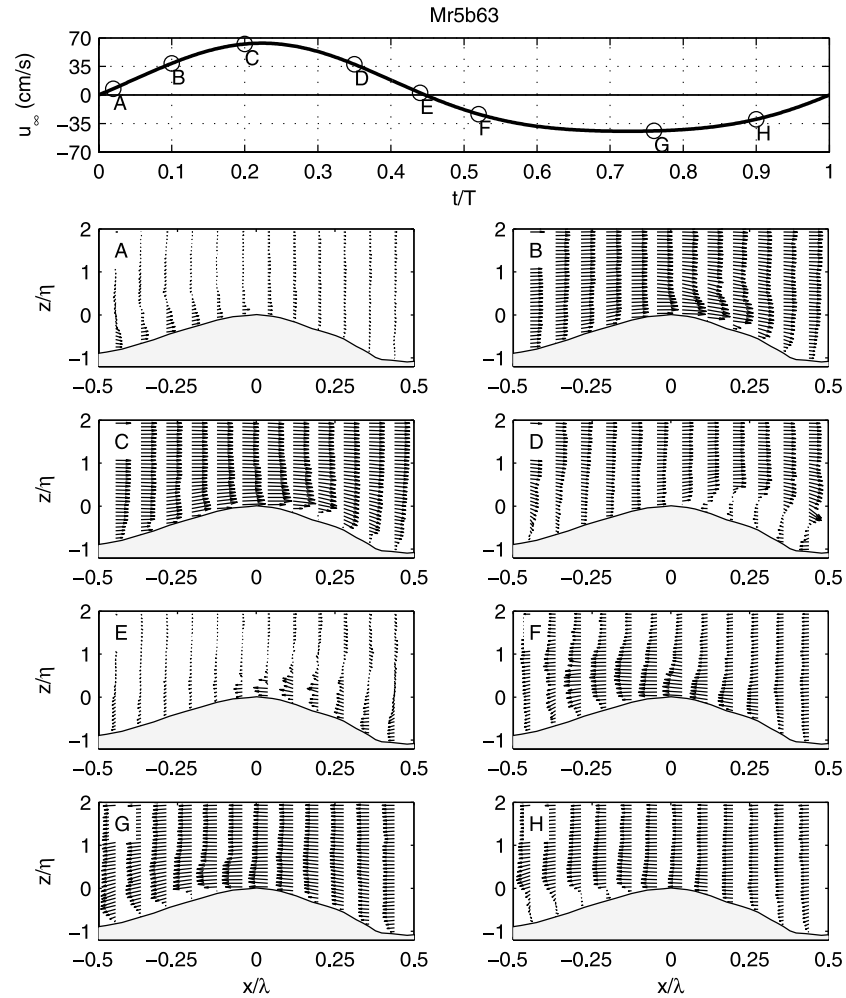

Figure 1. Velocity field for $z<2 \eta$ at eight phases for experiment Mr5b63. (top) Free-stream orbital velocity $u_{\infty}$. The circles on the time series of $u_{\infty}$ denote the phase of the flow. Positive, "onshore" flow is to the right in the velocity field plots. The velocity scale (horizontal distance between two grid points) is $0.80 \mathrm{~m} / \mathrm{s}$.

period for experiment Mr5b50. Experiments Mr5b50 and Mr5b63 have similar values of the flow period and rootmean-square orbital velocity, but in contrast to experiment Mr5b63, the flow was symmetric $(R=0.5)$ during experiment Mr5b50. In the symmetric case, strong flow separation occurs on both sides of the ripple and the intrawave flow field is near-symmetric about the ripple crest with similar velocity values and similarly sized vortices. This is most evident when comparing Figures $2 \mathrm{c}$ and $2 \mathrm{~g}$, which show the intrawave flow field near the timing of maximum onshore and offshore free-stream flow, respectively. Also Figures $2 \mathrm{a}$ and $2 \mathrm{f}$ show similar flow patterns near the moments of flow reversal.

\subsection{Velocities Near the Ripple Surface}

[41] As illustrated in Figures 1 and 2, very detailed measurements of the time-varying flow field over fullscale, mobile ripples have been obtained using the crosscorrelation PIV system. We will now examine the near-bed flow along the ripple, which is important in the context of sand pick-up and sand transport. We extract the horizontal velocity time series at the second point of measurement above the ripple surface; this corresponds to between approximately 6 and $12 \mathrm{~mm}$ above the bed. Figure 3 shows these near-bed horizontal velocity time series at eight locations along the ripple for experiment Mr5b63. Four velocity time series above the stoss side of the ripple (negative $x / \lambda$ values) and four velocity time series above the lee side of the ripple (positive $x / \lambda$ values) are shown. Figure 3 also includes the time series of the free-stream horizontal flow (measured at approximately three ripple heights above the ripple crest). The velocities are normalized by the maximum free-stream velocity, $u_{\infty, \max }$.

[42] The near-bed horizontal velocity time series are clearly different from the free-stream horizontal velocity. The maximum velocities near the ripple crest (Figures 3a and $3 \mathrm{~b}$ ) are up to 1.5 times higher than maximum freestream velocity. This is the result of the flow acceleration over the crest and the jet flow associated with the ejection of the lee side vortex (see also Figure 1). There is also a clear difference between the timings of the near-bed flow reversals and the free-stream flow reversal. Above the ripple slopes, near-bed flow reversals are ahead of free-stream flow reversals. In the following, we look deeper into these two aspects of the near-bed velocity: the timing of flow reversal and the velocity peaks. We do this for experiment Mr5b50 and Mr5b63 to examine the effect of flow asymmetry.

[43] Figure 4 shows the time difference $\Delta t_{\text {up }} / T$ between the off-onshore near-bed flow reversal and horizontal freestream reversal (upward zero-crossing), and time difference $\Delta t_{\text {down }} / T$ between the on-offshore near-bed flow reversal and free-stream reversal (downward zero-crossing) for experiment Mr5b50 (solid lines) and Mr5b63 (dashed lines). $\Delta t / T>0$ indicates flow reversal before free-stream reversal. As was already observed in Figure 3, on-offshore flow
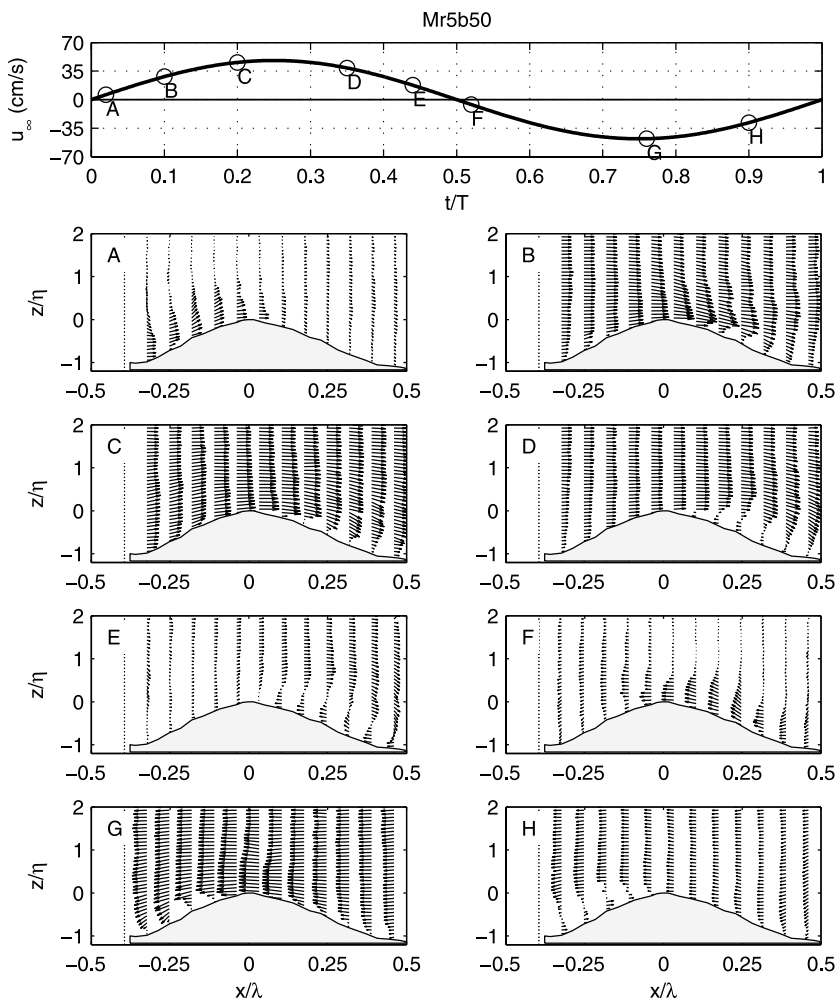

Figure 2. Velocity field for $z<2 \eta$ at eight phases for experiment Mr5b50. (top) Free-stream orbital velocity $u_{\infty}$. The circles on the time series of $u_{\infty}$ denote the phase of the flow. Positive, "onshore" flow is to the right in the velocity field plots. The velocity scale (horizontal distance between two grid points) is $0.80 \mathrm{~m} / \mathrm{s}$. 

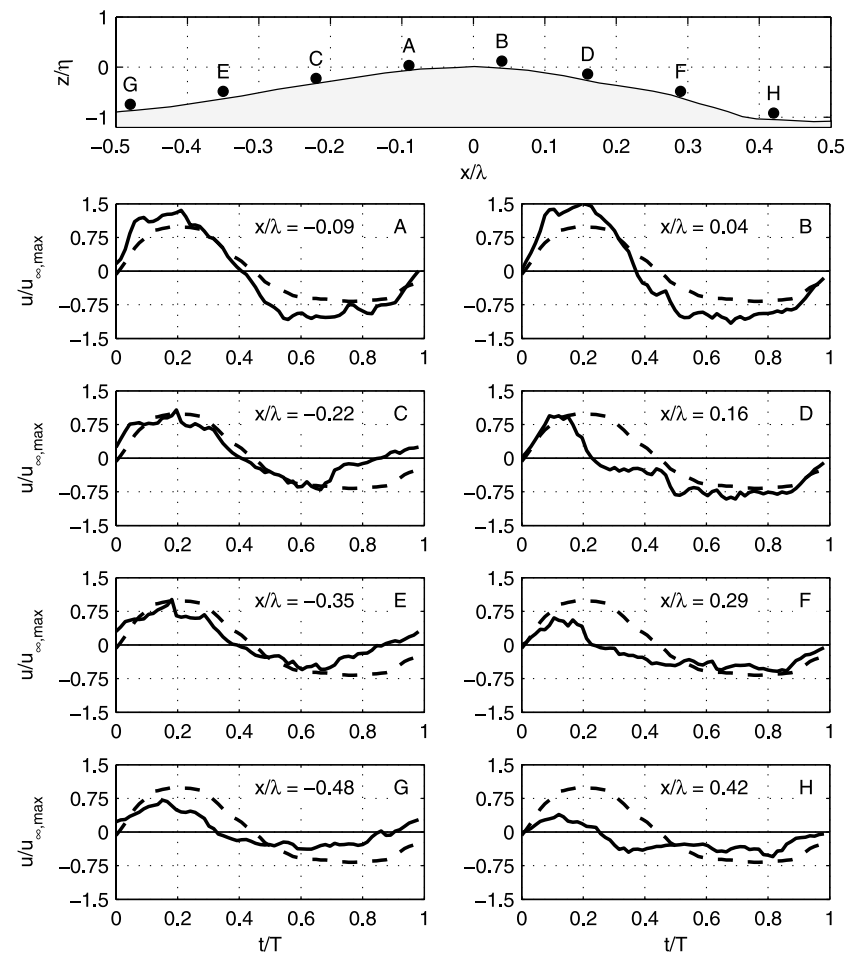

Figure 3. Free-stream horizontal velocity time series (dashed line) and horizontal velocity time series at the second point of measurement above the ripple surface (solid line) at eight horizontal locations along the ripple for experiment Mr5b63.

reversal, $\Delta t_{\text {down }} / T$, occurs on the ripple's lee slope before free-stream on-offshore reversal. Similarly, off-onshore flow reversal, $\Delta t_{\mathrm{up}} / T$, occurs on the ripple's stoss slope before free-stream off-onshore reversal.

[44] The plots of $\Delta t_{\text {down }} / T$ and $\Delta t_{\text {up }} / T$ reveal much about the initiation and development of the vortices. Looking first at the results for on-offshore flow reversal (Figure 4a), we see similar behavior for the two flows. On-offshore reversal first occurs around the middle of the lee slope $(x / \lambda \approx 0.2)$ at approximately $0.25-0.3 T$ before the free-stream reversal. The lee side vortex grows, filling the trough and causing flow reversal in the lower part of the slope. Flow reversal in the ripple trough occurs $0.1-0.15 T$ later than on the middle of the slope, which means that it occurs $0.1-0.15 T$ ahead of the free-stream reversal. Flow reversal near the ripple crest occurs slightly ahead $(0-0.1 T)$ of free-stream reversal, corresponding to the start of vortex ejection from the ripple slope into the main flow. There is a relatively strong time delay between flow reversal occurring at the middle of the lee slope and flow reversal occurring close to the crest.

[45] The behavior of the on-offshore flow reversal on the lee slope is mirrored by the behavior of the off-onshore flow reversal above the stoss slope (Figure $4 \mathrm{~b}$ ). However, for the asymmetric flow experiment Mr5b63 the off-onshore flow reversal above the stoss slope occurs generally somewhat later compared to the on-offshore flow reversal above the lee slope. This is the result of flow asymmetry: the lower offshore free-stream velocity produces a smaller vortex on the stoss slope than on the lee slope. Because of this asymmetry in vortex size, the stoss vortex, in contrast with the lee vortex, does not extend to the neighboring ripple. This is reflected in the difference between the timing of onoffshore flow reversal above the stoss slope and the timing of off-onshore flow reversal above the lee slope for experiment Mr5b63.

[46] Near-bed flow reversals are ahead of free-stream flow reversals because of vortex formation in each half flow cycle, but also affected by the fact that the flow in the boundary layer contains less inertia, because of the smaller velocities within the boundary layer. Therefore the flow can react more quickly to the varying pressure gradient and accelerates and decelerates earlier than the free stream. Consequently, the velocity inside the boundary layer is ahead in phase compared to the free-stream velocity. For laminar flow over a flat, smooth bed it can be shown theoretically that this phase lead is equal to $45^{\circ}$ [see, e.g., Nielsen, 1992]. For rough turbulent flow the phase lead becomes smaller than this. For example, O'Donoghue and Wright [2004] found that the near-bed velocity leads the main flow velocity by approximately $21^{\circ}$ on the basis of oscillatory flow tunnel measurements in sheet flow conditions (flat beds). This phase lead of $21^{\circ}$ corresponds to $\Delta t /$ $T=0.06$ while Figure 4 shows phase leads up to $\Delta t / T \approx$ 0.3 . Therefore the phase lead of near-bed flows in rippled bed conditions is primarily due to vortex formation.

[47] Figure 5 shows the maximum, $u_{\max }$, and the minimum, $u_{\text {min }}$, near-bed velocities as functions of the horizontal location along the ripple for experiment Mr5b50 (solid lines) and Mr5b63 (dashed lines). These velocity peaks have been normalized by the maximum, $u_{\infty, \max }$, and the minimum, $u_{\infty, \min }$, free-stream velocity, respectively. As already observed in Figure 3, Figure 5 shows that the near-ripple flow is very different from the free-stream flow in terms of velocity maxima. Both the symmetric and asymmetric experiment show that near the ripple crest, $-0.25 \leq x / \lambda \leq 0.15$, the flow acceleration over the crest during the onshore half cycle results in maximum near-bed velocities (Figure 5a) that are up to 1.5 times the maximum free-stream flow. During the offshore half cycle the flow is accelerated as well, resulting in strong near-bed offshore velocities (Figure 5b) in the case of Mr5b50. However, for the asymmetric flow experiment, Mr5b63, another process is of more importance: the jetting produced by the vortex shedding from the lee slope results in very strong near-bed offshore velocities that are up to 1.7 times the maximum offshore free-stream velocity.

[48] There is a progressive decrease in the near-bed velocity peaks moving from the crest into the trough, and in the ripple trough the velocity peaks are very much lower than the free-stream velocity peaks. The near-bed maximum onshore flow steadily increases up the stoss slope, reaches a maximum slightly onshore of the ripple crest and rapidly decreases from there to the ripple trough. Similar behavior can be observed for maximum offshore flow, but in the asymmetric flow case the decrease in velocity down the stoss side is less rapid.

\subsection{Time-Dependent Suspended Sand Concentration Field}

[49] An ABS and OPCON were used to measure the time-dependent suspended sand concentration field over the 
(a)

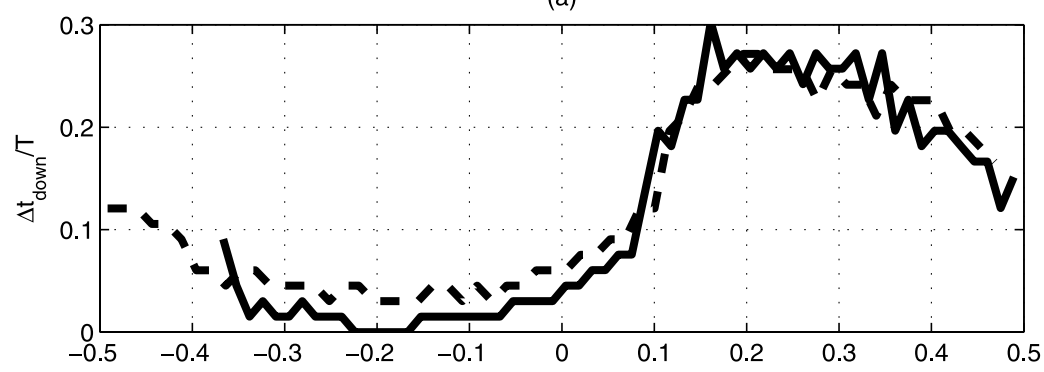

(b)

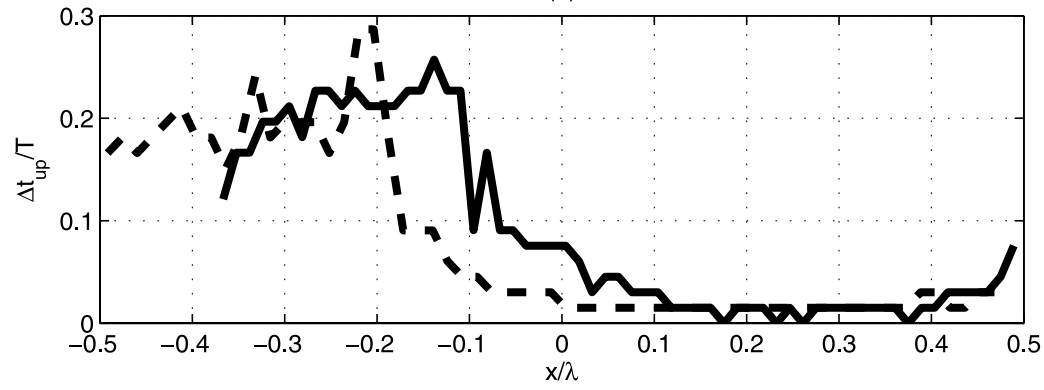

Figure 4. Timing of on-offshore flow reversal (a) and off-onshore flow reversal (b) near the ripple surface as function of the horizontal location along the ripple for experiments Mr5b50 (solid line) and Mr5b63 (dashed line). $\Delta t / T=0$ means flow reversal occurs at the same time as the free-stream reversal; $\Delta t / T>0$ means flow reversal occurs before the free-stream reversal.

ripples in experiments $\mathrm{Mr} 5 \mathrm{a} 63, \mathrm{Mr} 5 \mathrm{~b} 63$ and $\mathrm{Mr5c63.}$ Experiment Mr5a53 was a bedload-dominated condition with low levels of sand suspension during the flow cycle $(<0.2 \mathrm{~g} / \mathrm{l})$, which is close to the lower limit of the validity range of the ABS and OPCON measuring instruments. For this experiment the concentration measurements are sensitive to noise and consequently not very accurate. Therefore the time-dependent concentration measurements for condi-

(a)

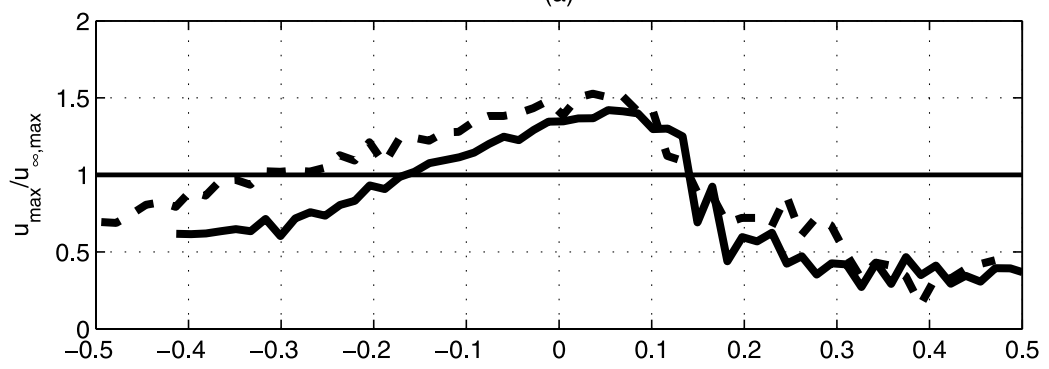

(b)

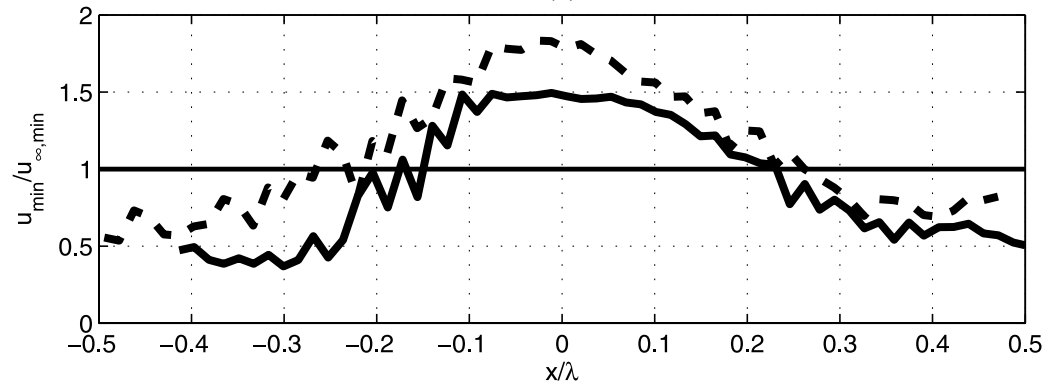

Figure 5. (a) Maximum onshore velocity and (b) maximum offshore velocity near the ripple surface as function of the horizontal location along the ripple for experiments Mr5b50 (solid line) and Mr5b63 (dashed line). The minimum and maximum velocity peaks, $u_{\min }$ and $u_{\max }$, have been normalized by the velocity peaks in the free stream, $u_{\min , \infty}$ and $u_{\max , \infty}$. 
tion Mr5a63 are not further considered in this paper. The concentration measurements for $\mathrm{Mr} 5 \mathrm{~b} 63$ are discussed below.

[50] Because of (small) fluctuations in the bed geometry and flow velocity in the neighborhood of the measurement position, a relatively large scatter occurs in the instantaneous concentration pattern [see also Bosman, 1982; Chen, 1992]. Assuming that these fluctuations are random, a good approximation of the concentration as a function of time can be found by ensemble averaging over a sufficiently large number of flow cycles. Since the ripples migrate, ensemble averaging over a number of flow cycles also implies bed averaging. It is assumed that a spatial resolution of 5\% of the ripple length is acceptable, which corresponds to $20 \mathrm{~mm}$ for experiment Mr5b63. Depending on the migration rate of the ripple above which measurements are made, this corresponds to ensemble averaging the OPCON concentrations over 12-30 flow cycles and the ABS concentrations over 22 flow cycles. With this number of flow cycles the typical time-dependent concentration behavior (number and timing of concentration peaks) is captured.

[51] The spatial pattern of the time-dependent concentrations above rippled beds is illustrated in Figure 6, which shows the concentrations at 18 flow phases for experiment Mr5b63 as measured by the ABS. The flow phases $t / T=0$, $0.22,0.45$ and 0.72 correspond to off-onshore flow reversal, maximum onshore flow, on-offshore flow reversal and maximum offshore flow, respectively.

[52] The general suspended sand concentration behavior, starting from off-onshore free-stream reversal at $t / T=0$, is as follows:

[53] 1. From $t / T=0$ to 0.11 there is a suspension cloud present above and offshore from the ripple crest. Flow is weakly onshore, and therefore this cloud moves little within this time while its size and concentration decrease because of settling, horizontal advection, and diffusion of the sand particles. This cloud originates from the vortex shed from the lee slope of the ripple located two ripple lengths onshore. At the same time a very small suspension cloud is generated at the stoss slope because of a weak and small vortex.

[54] 2. Close to maximum free-stream flow, from $t / T=$ 0.22 to 0.28 , near-bed sand concentrations are high, especially above the lee slope.

[55] 3. From $t / T=0.25$ to 0.44 the free stream is decelerating and the suspension cloud in the lee slope grows.

[56] 4. Between $t / T=0.44$ and 0.50 the suspension is lifted and ejected into the flow. At $t / T=0.56$ this main suspension cloud passes the ripple crest and extends to about $1.5 \eta$ above the ripple crest level.

[57] 5. The sand cloud travels offshore with the free stream and the concentrations within the cloud decrease as particles settle to the bed. At $t / T=0.78$, the cloud passes the neighboring offshore ripple and, after losing even more sand, the second offshore ripple at $t / T=0.94$.

[58] The time-dependent concentrations at four elevations above the ripple crest (at $x / \lambda=0$ and $\mathrm{z} / \eta=0$ ) measured by the ABS and OPCON are shown in Figure 7 for experiment Mr5b63. In the Figure 7, top, the orbital excursion of the free stream (left) and the free-stream orbital velocity (right) are plotted.
[59] In general the ABS- and OPCON-measured concentrations show a very similar behavior. Three main concentration peaks can be observed during the flow cycle, which appear to occur almost simultaneously at different elevations above the bed:

[60] 1. The largest concentration peak (further referred to as "peak 1 ") occurs around $t / T \approx 0.55$. The peak is associated with the passage of a cloud of suspended sand generated by vortex shedding from the lee side of the ripple around the time of on-offshore flow reversal $(t / T \approx 0.45)$.

[61] 2. A second peak ("peak 2 ") occurs at $t / T \approx 0.7-0.8$. This peak is due to the passage of an advected suspension cloud generated on the lee slope of the neighboring onshore ripple. Peak 2 is lower than peak 1 because of diffusion and settling of the sand particles during advection.

[62] 3. "Peak 3 " occurs at $t / T \approx 0.9-1.0$ and is caused by the passage of an advected suspension cloud. This cloud is the remainder of the sand cloud associated with the vortex shed from the lee slope of the ripple located two ripple lengths onshore. The difference between the orbital excursion of the free stream at $t / T=0.55$ and $t / T=0.95$ is $0.76 \mathrm{~m}$ (Figure 7, top left). Within this time, peak 1 travels over two ripple lengths, which corresponds to $2 \times 0.41=0.82 \mathrm{~m}$. This implies that peak 1 travels on average slightly faster than the free-stream flow.

[63] Close to the ripple crest, two other concentration peaks are present, one occurring at $t / T=0.1-0.2$ and one at $t / T \approx 0.3$. These are associated with the passage of a sand-laden vortex ejected from the stoss slope around the time of off-onshore flow reversal $(t / T=0)$ and with maximum onshore flow. The latter creates a near-bed plume of sand that originates from the mobile layer on the stoss slope and moves onshore over the ripple crest. Higher up in the flow (best seen at $z / \eta=1.13$ ), the time-dependent concentrations are less coherent because of diffusion and settling of the sand particles and breaking up of the vortices. Peaks 1, 2, and 3 are still visible but peak 1 no longer dominates.

\subsection{Timing of Peaks in Suspended Sand Concentration}

[64] The timing of the peaks in suspended sand concentration is of crucial importance for the net sand transport. Figure 8 shows the time difference $\Delta t / T$ between the timing of the concentration peak at two different elevations above the ripple crest level relative to on-offshore free-stream reversal (at $t / T=0.45$ ) for experiment $\mathrm{Mr} 5 \mathrm{~b} 63$ as measured by the ABS. $\Delta t / T>0$ means concentration peak occurs after on-offshore free-stream reversal. Different lines are used in Figure 8 to distinguish between peak 1, peak 2, and peak 3 (see Figure 7).

[65] The general behavior is as follows. Just after onoffshore free-stream reversal $(\Delta t / T=0)$ a sand-rich cloud associated with vortex shedding appears above the ripple trough $(x / \lambda=0.5)$. This cloud (peak 1$)$ is advected by the offshore flow, passes the ripple crest $\approx 0.15 T$ after onoffshore free-stream reversal and travels with a fairly constant celerity. At $\Delta t / T=0.25$ the suspended cloud reaches the next offshore ripple. At this stage it becomes a "peak 2", and it travels further offshore with a slightly higher celerity, again quite constant, associated with the higher free-stream velocity, which has its peak at $\Delta t / T=0.27$. 

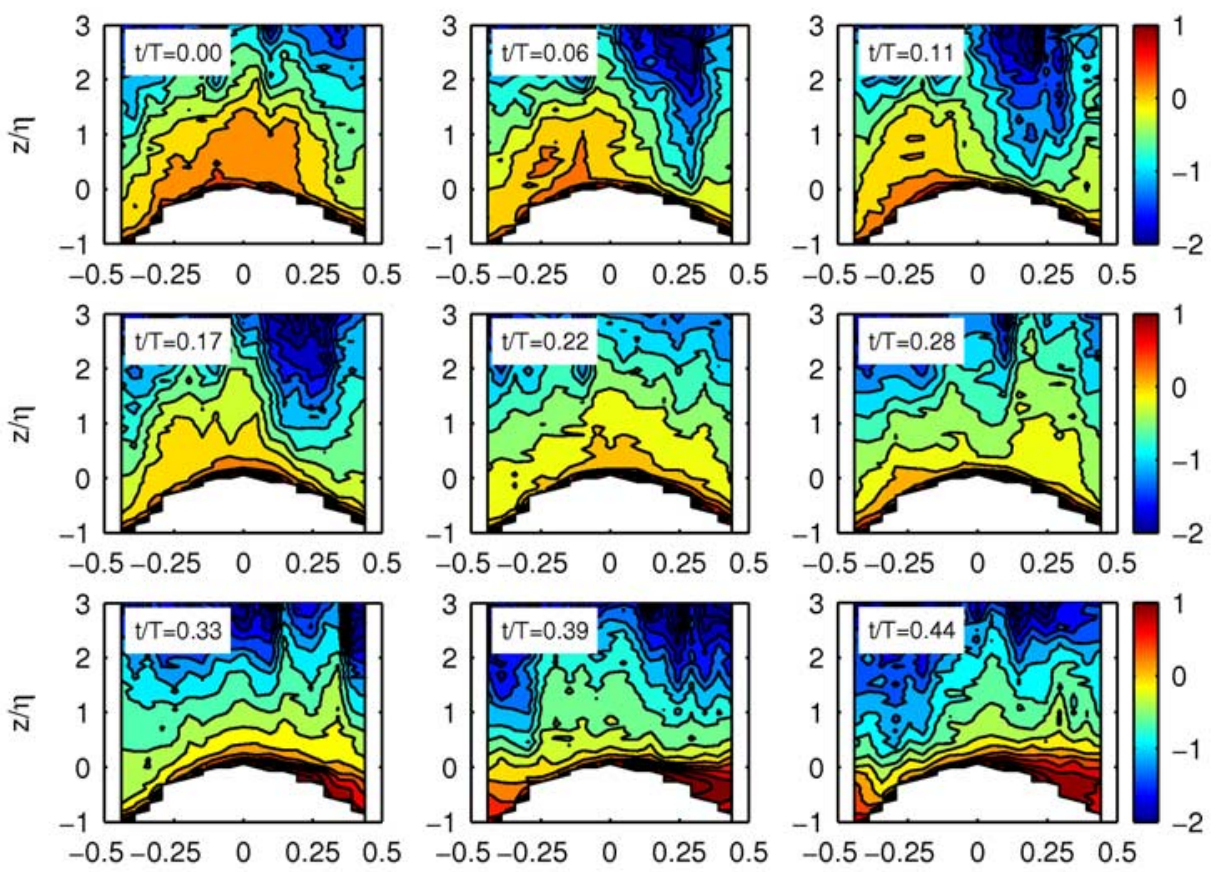

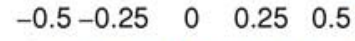
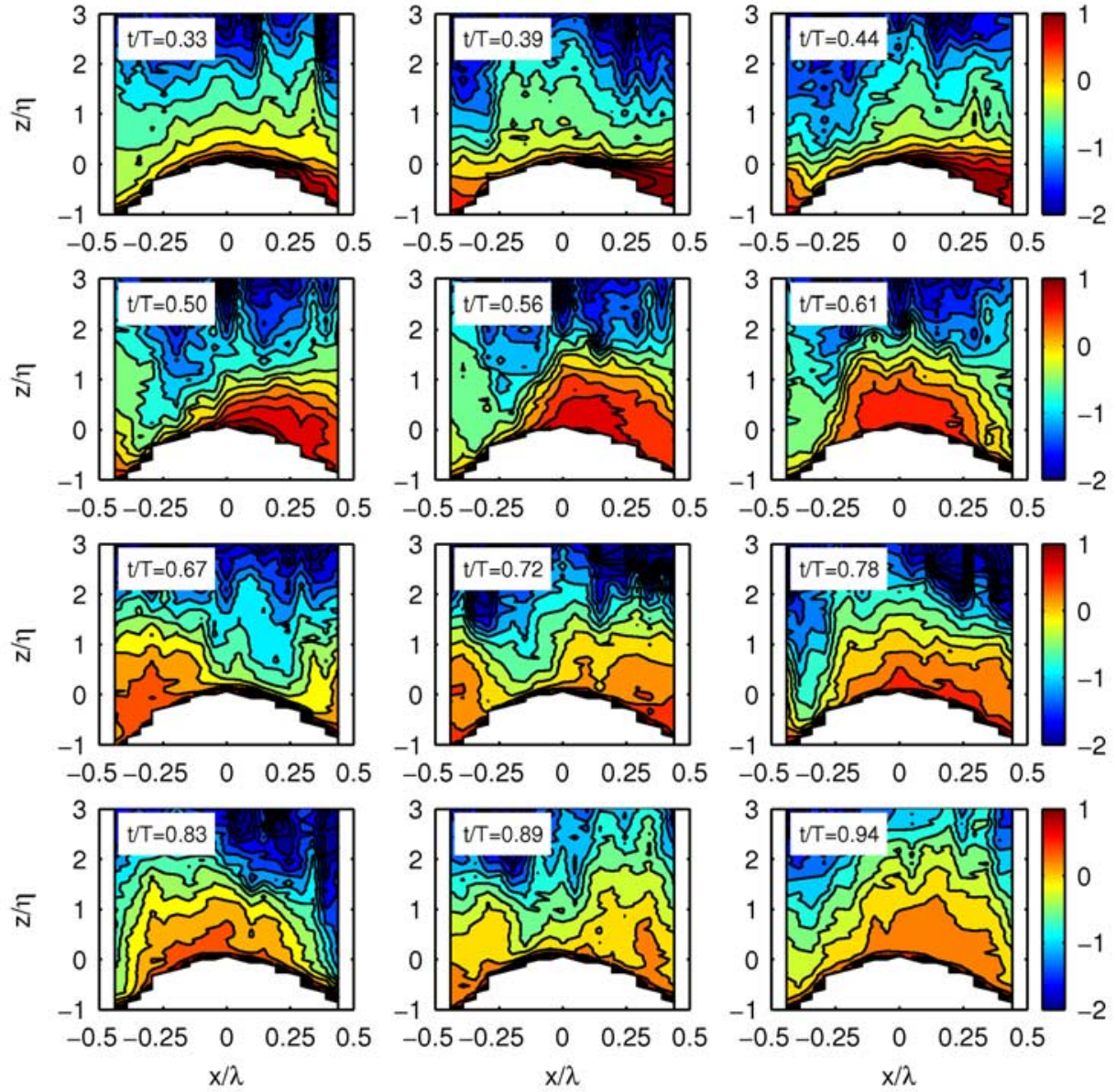

Figure 6. Time-dependent concentration field ( $\log 10$ values) around the ripple at 18 phases during the flow cycle for experiment Mr5b63 as measured by the acoustic backscatter system (ABS).

Between $\Delta t / T=0.35$ and $\Delta t / T=0.45$ the suspended cloud reaches the ripple located two ripple lengths offshore. As free-stream offshore flow is decelerating, the suspended cloud (peak 3) is slowed down, but is just able to pass the ripple crest before the free stream reverses from offshore to onshore (at $\Delta t / T=0.55$ ).

[66] The difference between the timing and celerity of the concentration peaks at $z / \eta=0.5$ and $z / \eta=2.0$ is small. This suggests that the sand-rich cloud associated with vortex shedding is coherent, quickly ejected into the flow (covering a layer of at least two ripple heights), and stays coherent once it has been ejected.

\subsection{Time-Dependent Sand Flux Field}

[67] For 2-D turbulent flow, we can split the horizontal and vertical velocity and the volumetric sand concentration into a time-averaged part (denoted by an overbar), a 

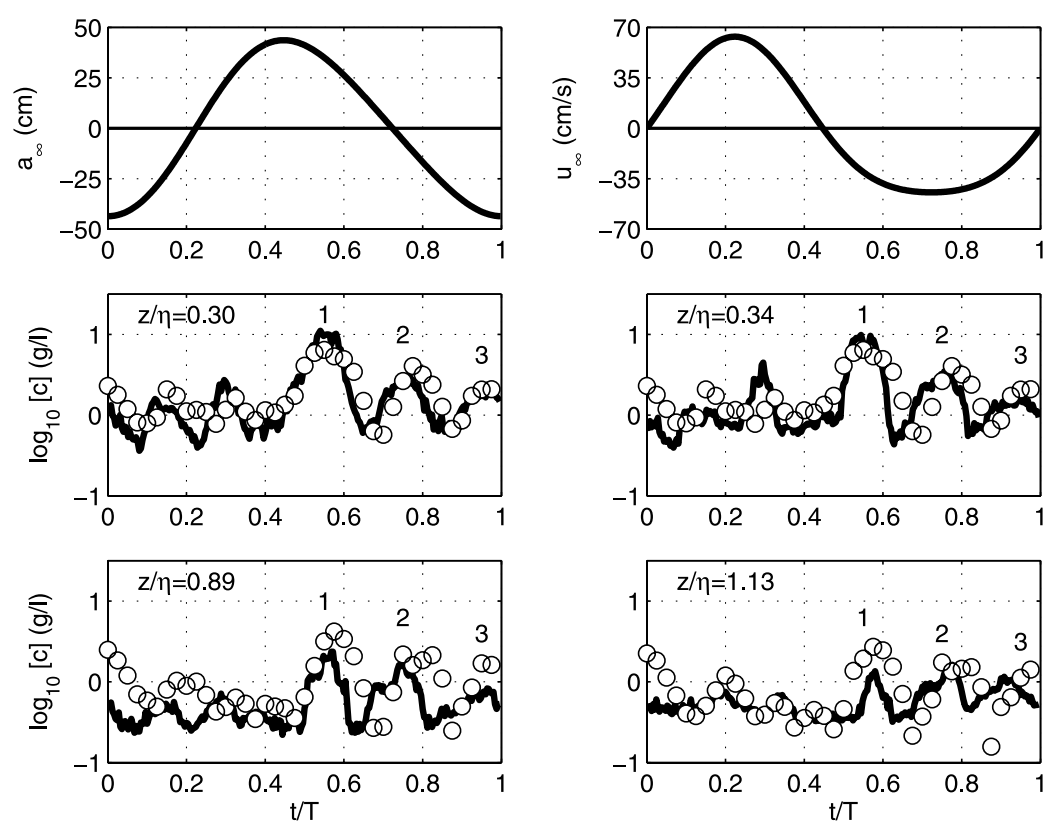

Figure 7. Ensemble-averaged concentrations above the ripple crest $(x / \lambda=0)$ at four vertical elevations for experiment Mr5b63 as measured by the ABS (circles) and optical concentration meter (OPCON) (solid line). (top, left) Free-stream orbital excursion. (top, right) Free-stream orbital velocity.

periodic component (denoted by a tilde) and a turbulent component (denoted by a prime):

$$
\begin{aligned}
u(x, z, t) & =\bar{u}(x, z)+\widetilde{u}(x, z, t)+u^{\prime}(x, z, t) \\
w(x, z, t) & =\bar{w}(x, z)+\widetilde{w}(x, z, t)+w^{\prime}(x, z, t) \\
c(x, z, t) & =\bar{c}(x, z)+\widetilde{c}(x, z, t)+c^{\prime}(x, z, t)
\end{aligned}
$$

where $x$ is the horizontal and $z$ the vertical coordinate. The instantaneous sand flux in $[\mathrm{m} / \mathrm{s}]$ is:

$$
\begin{aligned}
& \varphi_{x}(x, z, t)=u(x, z, t) c(x, z, t)(\text { in } x-\text { direction }) \\
& \varphi_{z}(x, z, t)=w(x, z, t) c(x, z, t)(\text { in } z-\text { direction })
\end{aligned}
$$

The sand fluxes are computed by combining the ensembleaveraged flow field measured using PIV and the ensembleaveraged ABS volumetric concentration field. The temporal resolution of the PIV-measured velocity field is $0.076 \mathrm{~s}$ and the horizontal and vertical resolution is $7 \mathrm{~mm}$. The ABSmeasured concentration field has a temporal resolution of $0.125 \mathrm{~s}$, a horizontal resolution of $20 \mathrm{~mm}$ and a vertical resolution of $5 \mathrm{~mm}$. Through nearest neighbor interpolation, the velocity field and concentration field with the same temporal and spatial resolution are determined. The sand flux field obtained from the product of the velocity and concentration fields has a temporal resolution of $0.125 \mathrm{~s}$, a horizontal resolution of $20 \mathrm{~mm}$ and a vertical resolution of $7 \mathrm{~mm}$.
[68] Figure 9 shows the measured sand flux field corresponding to eight phases within the flow period for experiment Mr5b63. (We do not present the sand fluxes for experiment $\mathrm{Mr} 5 \mathrm{c} 63$, since the ripple variability was too large.) Figure 9, top, shows the free-stream orbital velocity $u_{\infty}$ and also shows the phases for which the eight velocity fields are presented. Note that the full measurement at each phase consists of 19 vertical profiles over the length of the ripple but only nine profiles are shown for clearer presentation. Onshore, positive flux is directed to the right.

[69] We discuss the sand flux behavior starting from offonshore free-stream reversal at $t / T=0$. With reference to Figure $9(\mathrm{a}-\mathrm{h})$ and Figures 1 and 6 , which show the timedependent flow and concentration fields, respectively, the general flux behavior is as follows:

[70] 1. (a): Off-onshore flow reversal. Although there is quite a large amount of the sand in suspension, the sand fluxes are small since the free-stream orbital velocity is zero. Fluxes are onshore directed and highest above the stoss slope, associated with the stoss vortex.

[71] 2. (b): Free stream is accelerating onshore. The flow accelerates as it rises up the stoss slope, producing high near-bed onshore-directed sand fluxes above the ripple crest and above the lee slope.

[72] 3. (c): Time of maximum onshore free-stream velocity. Flow acceleration over the ripple crest persists generating a strong onshore sand flux close to the ripple crest, which consists of a near-bed plume of sand that is thrown from the stoss slope over the ripple crest. There is strong separation in the lee of the ripple with flow starting to reverse near the bed on the lee slope. As a consequence, sand fluxes are low here.

[73] 4. (d): Onshore free stream is decelerating. Flow reversal has occurred on the lee slope resulting in a well- 

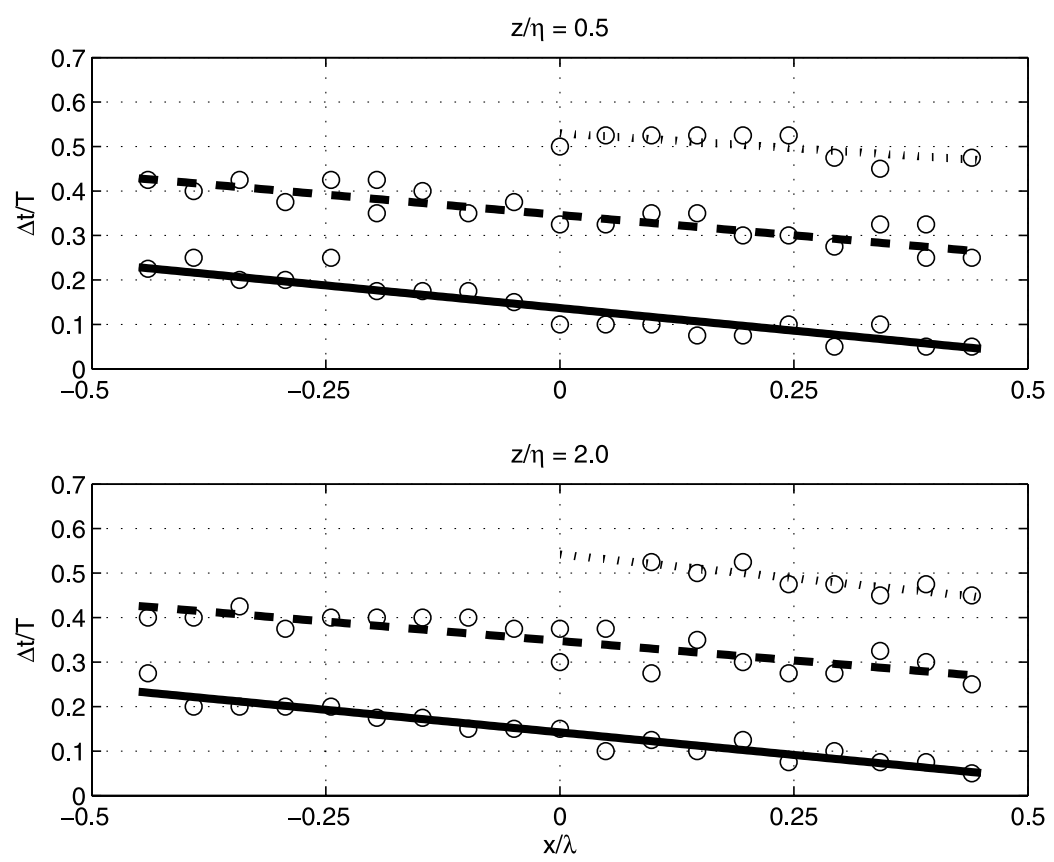

Figure 8. Timing of concentration peak 1 (solid lines), concentration peak 2 (dashed lines), and concentration peak 3 (dotted lines) at two different elevations above the ripple crest level as function of the horizontal location along the ripple for experiment Mr5b63. $\Delta t / T=0$ refers to the moment of onoffshore free-stream reversal; $\Delta t / T>0$ means that the concentration peak occurs after on-offshore freestream reversal.

defined vortex and strong offshore fluxes between $0<x / \lambda<$ 0.25 above the lee slope.

[74] 5. (e): Free stream is close to on-offshore flow reversal. The free-stream velocity is low and the lee vortex starts to lift from the bed, producing relatively high, offshore-directed fluxes above the lee slope.

[75] 6. (f): Soon after on-offshore flow reversal. Freestream flow reversal has just occurred and the free-stream velocity is very low. However, offshore sand fluxes at $0<$ $x / \lambda<0.25$ are relatively large and extend up to one ripple height above the ripple crest. This is due to the ejection of the large lee side vortex.

[76] 7. (g): Close to the time of maximum offshore freestream velocity. Fluxes above the lee slope are relatively large and in the offshore direction as a result of offshore flow and the advection of the coherent vortex generated in the lee slope of the adjacent onshore ripple.

[77] 8. (h): Near off-onshore flow reversal. Small offshore sand fluxes can be observed above the ripple lee slope reflecting the travel of a suspension cloud originating from the vortex shed from the lee slope of the ripple located two ripple lengths onshore.

\section{Time-Averaged Behavior}

\subsection{Time-Averaged Velocities}

[78] The time-dependent velocities can be time-averaged to reveal the residual flow patterns (streaming), $\bar{u}(x, z)$ and $\bar{w}(x, z)$. These depend strongly on the relative size and strength of the vortices. The time-averaged velocity field presents a different perspective on the flow and provides a useful point of comparison with numerical model predictions.

[79] Figure 10 presents the time-averaged velocity field for experiments Mr5b50, Mr5b54, Mr5b58 and Mr5b63 with increasing degree of flow asymmetry. Figure 10 shows the influence of flow asymmetry on the time-averaged velocity field. Asymmetry in the free stream and the consequent asymmetry in vortex formation produces steady circulation cells with high offshore mean flow up the lee slope and above the ripple crest level on the stoss side of the ripple. The strong offshore streaming is mostly contained within 1.5 ripple heights above the crest level and is balanced by weaker onshore streaming up the stoss slope and higher in the flow. It should be noted that PIV measured the velocities of the suspended sand, not the fluid. As a result, the velocities contain an extra vertical component due to the settling of the sand particles which is most noticeable high in the flow where time-averaged velocities are small.

[80] The 2D, time-averaged velocity fields can be averaged over the ripple length to produce the time- and horizontally-averaged velocity profiles, $\langle\bar{u}(z)\rangle$. Figure 11 shows these streaming profiles above the ripple crest for experiments Mr5b50, Mr5b54, Mr5b58 and Mr5b63 starting from the ripple crest level $z=0$ to $z=4 \eta$.

[81] The strong effect of flow asymmetry on the time- and horizontally-averaged velocity profile is clear in Figure 11. Increasing asymmetry leads to an increasingly offshore near-bed streaming and an increasingly onshore drift higher up in the flow. The absolute magnitudes of the net velocities are low $(0-0.07 \mathrm{~m} / \mathrm{s})$ and the magnitudes relative to the 

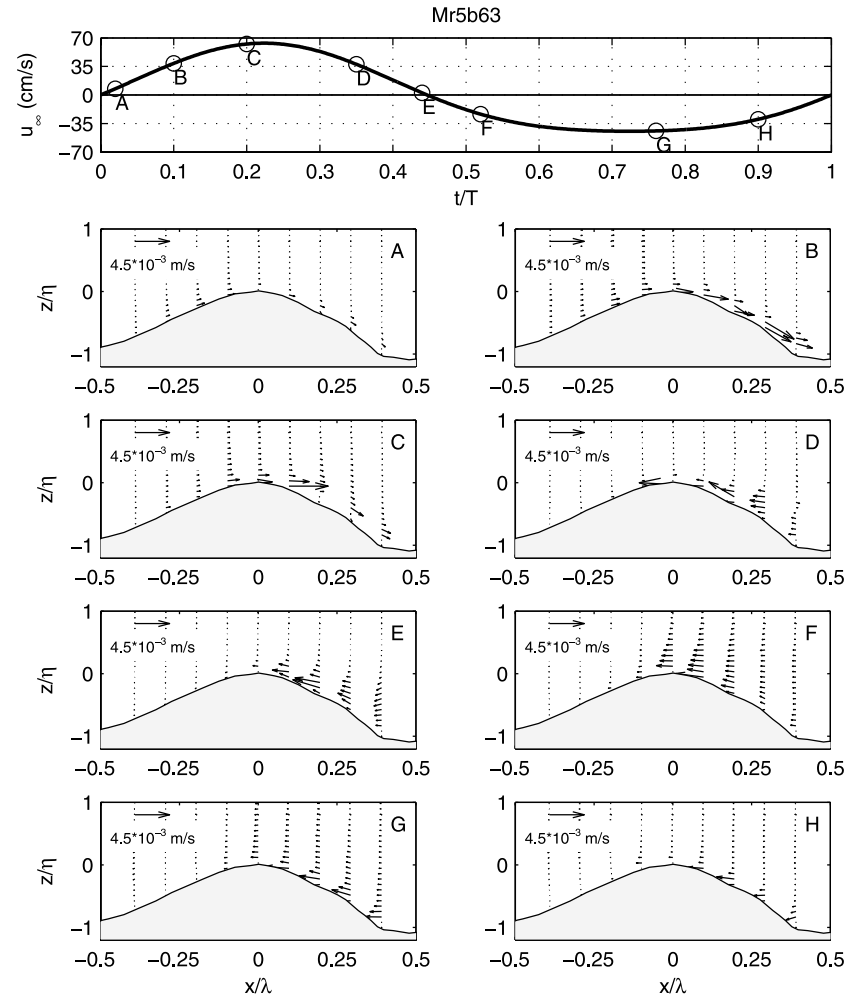

Figure 9. Sand flux field for $z<\eta$ at eight phases for experiment Mr5b63. (top) Free-stream orbital velocity. The circles on the time series of $u_{\infty}$ denote the phase of the flow. Positive, "onshore" flux is to the right.

main flow velocity $\left|\langle\bar{u}(x, z)\rangle / \sqrt{2} u_{r m s}\right|$ are between 0 and 0.13 . Note that a small onshore streaming $(0-0.01 \mathrm{~m} / \mathrm{s})$ is present for experiment Mr5b50, which may be an effect of non-perfectly-symmetric flow, the measurements or the data processing.
[82] The observed streaming profile looks similar to the tunnel measurements by Ribberink and Al-Salem [1995] and O'Donoghue and Wright [2004] for regular asymmetric flows and sheet flow (flat bed) sand transport conditions. The boundary layer streaming in the case of flat beds can be explained by the flow asymmetry, causing a difference in the generated turbulent energy during both half flow cycles [see also Trowbridge and Madsen, 1984a, 1984b], whereas over rippled beds, the boundary layer streaming is due to vortex generation and flow acceleration over the ripple crests. Since there is no net water flow over the complete cross section of the test section in the tunnel, the net flow close to the bed is compensated by a positive flow, $\langle\bar{u}(x, z)\rangle$ $>0$, in the free stream, which can be observed for $z / \eta>1.0$. Similar to this offshore near-bed streaming, an offshore streaming can be expected at the upper boundary of the fluid domain, which is formed by the tunnel roof. The tunnel roof is located $0.5 \mathrm{~m}$ above the initial flow bed level, corresponding to $z / \eta \approx 7$. Unfortunately, the PIV measurements could not be extended further than approximately four ripple heights above the ripple crest level.

[83] When considering these measured streaming profiles, it should be realized that, in contrast to flow under actual waves, vertical orbital velocities are not simulated in flow tunnels. Therefore an onshore streaming component associated with the interaction between the horizontal and vertical orbital flow field [see Longuet-Higgins, 1953; Davies and Villaret, 1999] is not present in flow tunnels.

[84] Although the net streaming is generally small compared to the horizontal orbital velocities, it could be potentially important for the net sand transport because of its presence in a near-bed layer with relatively high sand concentrations. The importance of the contribution of this streaming or current-related transport is considered in the next section.
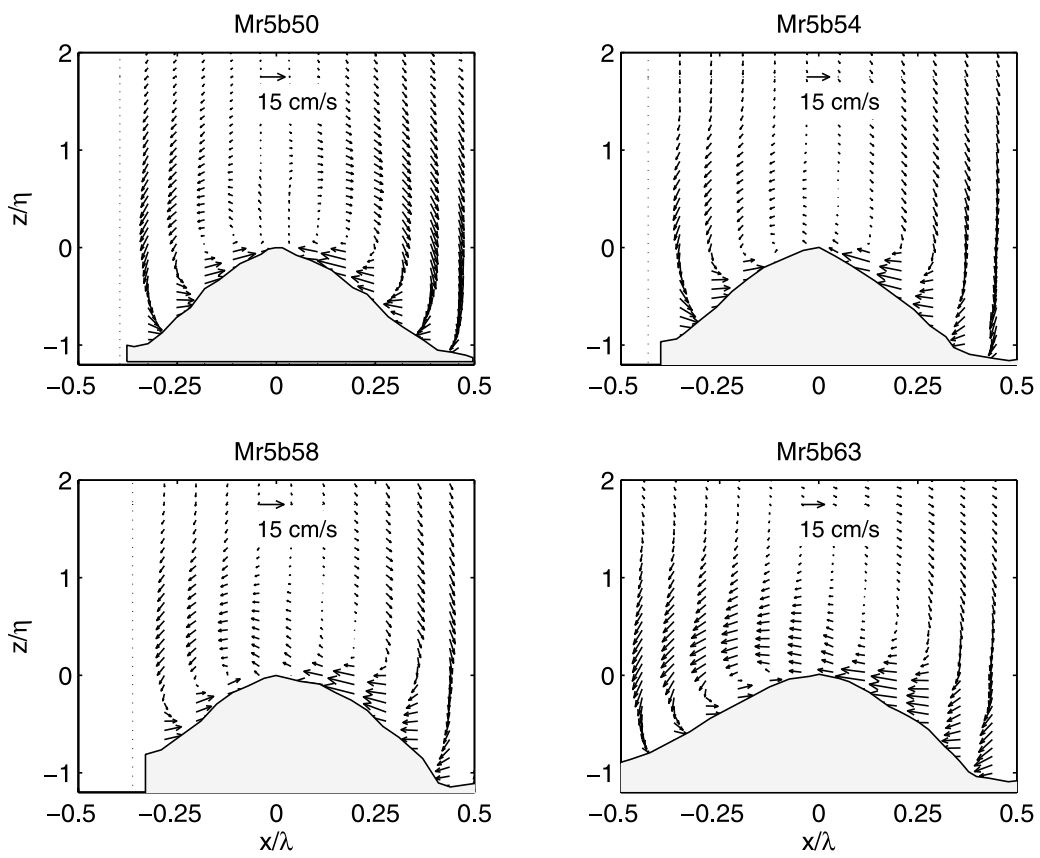

Figure 10. Time-averaged flow field for experiments Mr5b50, Mr5b54, Mr5b58, and Mr5b63. 

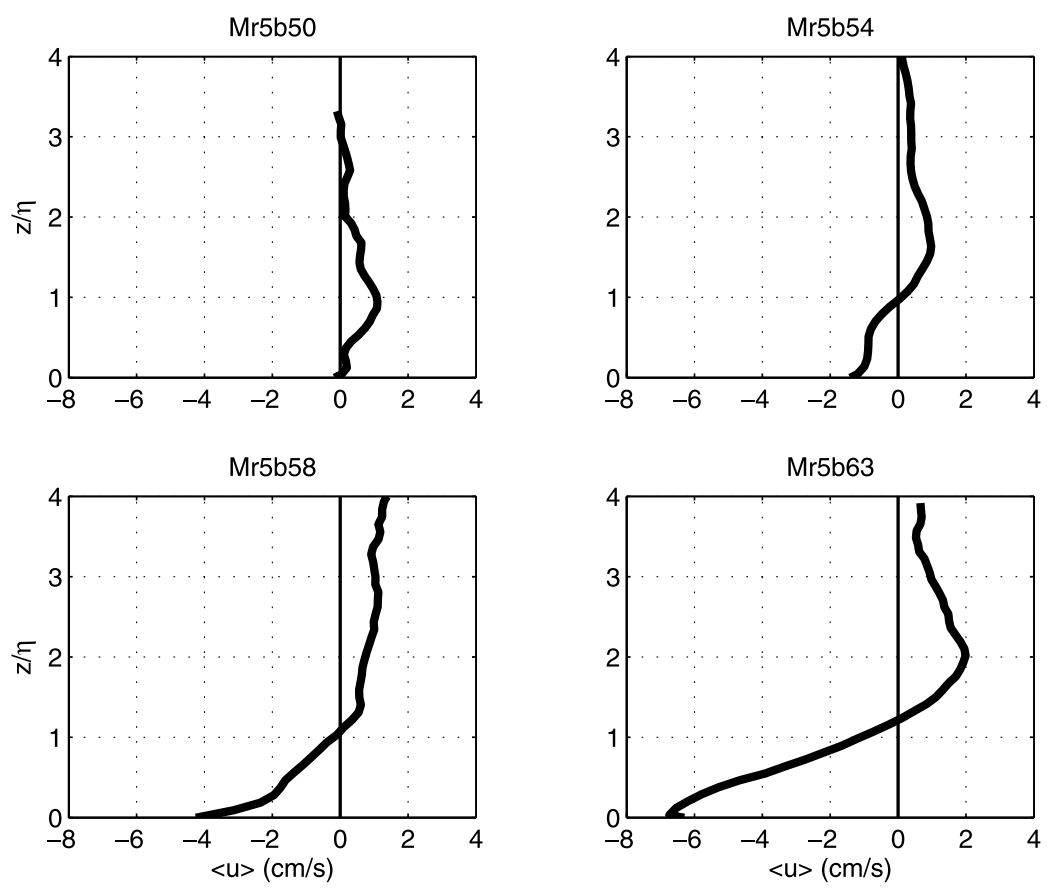

Figure 11. Time-averaged and horizontally averaged velocity profiles for experiments Mr5b50, Mr5b54, Mr5b58, and Mr5b63.

\subsection{Time-Averaged Suspended Sand Concentrations and Fluxes}

[85] Figure 12 shows that the time- and bed-averaged concentrations measured by the ABS, OPCON and TSS are similar for experiment Mr5b63 and Mr5c63 (ABS and OPCON concentration measurement for experiment
Mr5a63 are not considered, see Section 3.3). The large similarity between the ABS measurements and the OPCON and TSS measurements was expected since the ABS has been tuned on the time- and bed-averaged concentration measurements by the OPCON and TSS (with a constant factor).
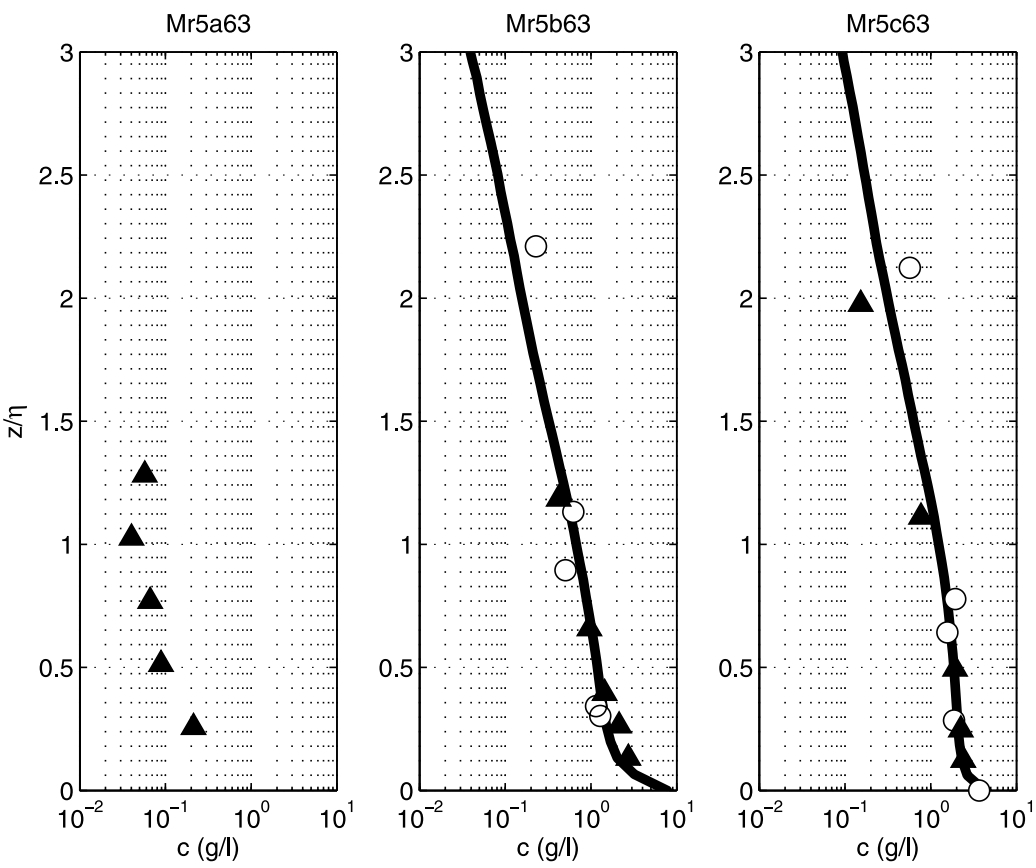

Figure 12. Time- and bed-averaged ABS (solid lines), OPCON (open circles), and transverse suction system (TSS) (solid triangles) concentrations for experiments Mr5a63, Mr5b63, and Mr5c63. 

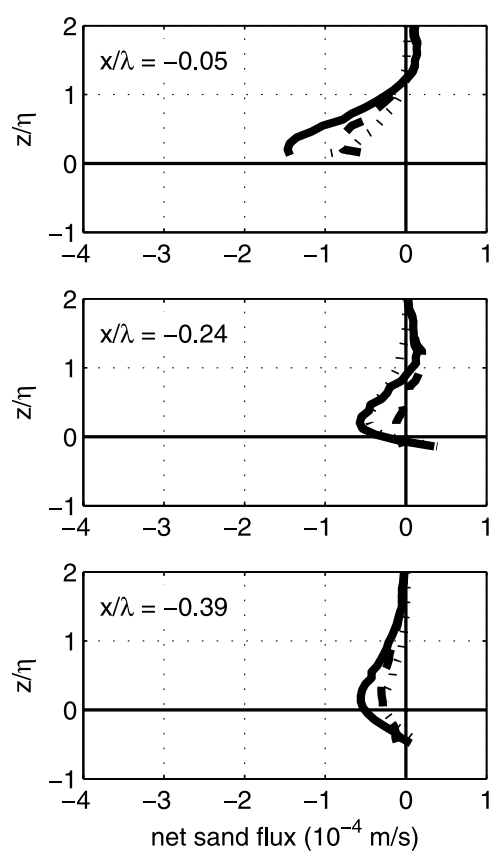
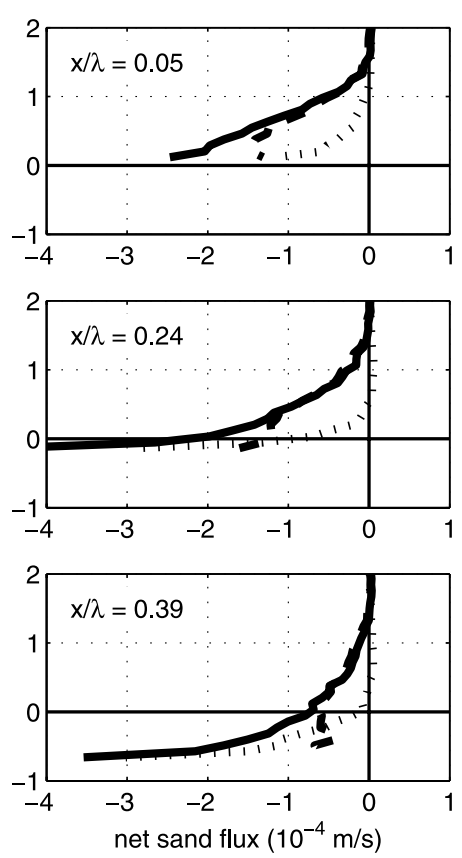

Figure 13. Profiles of the wave-related (dashed line), current-related (dotted line), and total net horizontal suspended sand flux (solid line) at six horizontal locations along the ripple for experiment Mr5b63. by:

[86] The time-averaged suspended sand fluxes are given

$$
\begin{aligned}
& \bar{\varphi}_{\mathrm{x}}=\bar{u}(x, z) \bar{c}(x, z)+\overline{\widetilde{u}(x, z, t) \widetilde{c}(x, z, t)} \\
& \bar{\varphi}_{\mathrm{z}}=\bar{w}(x, z) \bar{c}(x, z)+\overline{\widetilde{w}(x, z, t) \widetilde{c}(x, z, t)}
\end{aligned}
$$

assuming that the contributions of the turbulent components are negligible [Chen, 1992]. The first term on the right-hand side of equations (11) and (12) is the net current-related sand flux and the second term is the wave-related sand flux. Figure 13 shows these components of the net horizontal sand flux at six locations along the ripple for experiment Mr5b63. The profiles start at the second nonzero value above the ripple surface, which corresponds to $10 \mathrm{~mm}$ above the bed.

[87] Figure 13 shows that net sand fluxes are larger above the lee side of the ripple (positive $x / \lambda$ values) than above the stoss side of the ripples (negative $x / \lambda$ values). This is due to flow asymmetry which creates asymmetry in the vortex formation and in the steady circulation cells (see also Figures 1 and 10). In general, net sand fluxes below the ripple crest level on the lee side are dominated by the current-related component (dotted lines), with sand fluxes directed toward the ripple crest due to circulation cells that appear in the time-averaged flow field above ripples. Above the ripple crest, the net wave-related sand flux (dashed lines) dominates with relatively strong offshore sand fluxes above the lee slope due to offshore vortex shedding, while above the stoss slope wave-related net sand fluxes are smaller. The net sand fluxes are mostly contained in the layer $z / \eta<1.5$.
[88] If we vertically integrate these net suspended sand fluxes we get the net suspended sand transport rates (Figure 14). Again we distinguish between the waverelated, current-related and the total net suspended sand transport rate. Except for one location, the wave-related suspended sand transport is negative ("offshore directed") along the ripple. The highest negative wave-related suspended transport rates are found above the lee side of the ripple. The current-related suspended sand transport is negative at all locations along the ripple and displays less horizontal variation than the wave-related transport component. As a result, the total net suspended sand transport is negative at all locations with higher negative transport rates above the lee slope. The ripple-averaged total net suspended transport rate is $-8.2 \times 10^{-6} \mathrm{~m}^{2} / \mathrm{s}$ of which the largest part $(61 \%)$ is wave-related. The measured total net sand transport was $-3.7 \times 10^{-6} \mathrm{~m}^{2} / \mathrm{s}$ (see Table 1). This means that between the ripple surface and approximately $10 \mathrm{~mm}$ above the ripple surface a positive ("onshore directed") net transport (bedload and suspended load) was present with a magnitude of $4.5 \times 10^{-6} \mathrm{~m}^{2} / \mathrm{s}$.

[89] It is often hypothesized that bedload and near-bed suspended transport are the forcing mechanism for ripple migration [Traykovski et al., 1999]. During experiment Mr5b63, the ripples migrated onshore with a fairly constant rate of $18 \mathrm{~mm} / \mathrm{min}$. According to Hoekstra et al. [2004], the net transport associated with ripple migration can be estimated with:

$$
\left\langle q_{\mathrm{mig}}\right\rangle=c_{r} f\left(1-\varepsilon_{\mathrm{p}}\right) \eta
$$

where $c_{\mathrm{r}}$ is the ripple migration rate, $f$ the dimensionless shape factor and $\varepsilon_{\mathrm{p}}(\approx 0.4)$ the bed porosity. The shape factor $f$ is equal to 0.5 in case of idealized triangular 


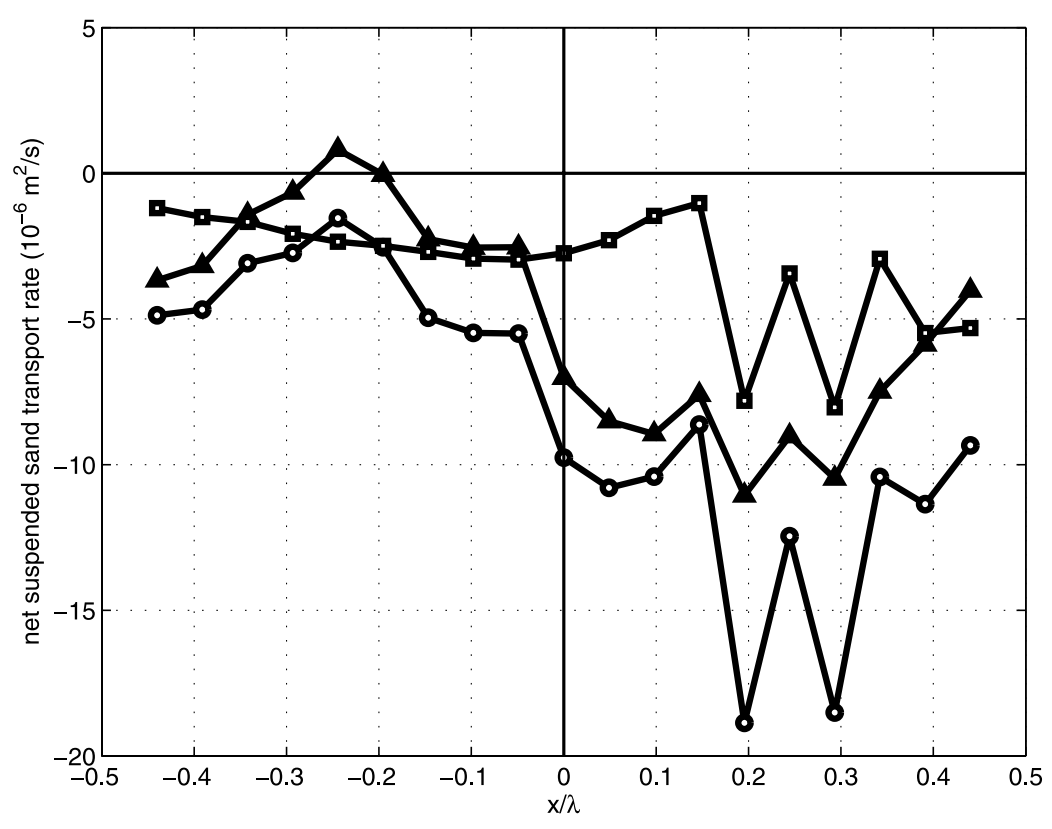

Figure 14. Net wave-related (solid triangles), current-related (open squares), and total net horizontal suspended sand transport rate (open circles) as function of the horizontal location along the ripple for experiment Mr5b63.

bedforms and zero transport at the ripple trough level. For $f=0.5$ we find $\left\langle q_{\mathrm{mig}}\right\rangle=6.8 \times 10^{-6} \mathrm{~m}^{2} / \mathrm{s}$, which is in reasonable agreement with the derived near-bed transport considering the uncertainties in the measurements. For experiment Mr5b63, the total net sand transport is thus offshore-directed as a result of the greater offshore-directed suspended transport relative to the smaller onshore-directed bedload and near-bed suspended transport.

[90] Table 1 shows that the net sand transport rate is also offshore-directed for experiment Mr5c63. However, the net sand transport is in the onshore direction for experiment Mr5a63, related to the fact that the onshore-directed bedload transport was larger than the offshore-directed suspended load transport. Similar to experiment Mr5a63, the field observations by Traykovski et al. [1999] show that bedload transport is dominant and that the onshore ripple migration accounts for an order of magnitude more sand transport than the net offshore-directed suspended transport.

[91] The relative importance of bedload and suspended load is usually described by the ratio of shear velocity, $u_{*}$, and the fall velocity of suspended sand, $w_{\mathrm{ss}}$. The $u_{*}$ value was calculated using the friction formula of Swart [1974] with a roughness of $2.5 D_{50}$ and $w_{\mathrm{ss}}$ was calculated using the formula of Soulsby [1997] with $D=0.8 D_{50}$ as representative grain size of suspended sand. For experiments Mr5a63, Mr5b63 and Mr5c63 this gave $u_{*} / w_{\mathrm{ss}}$ values of $0.52,0.82$ and 0.96. Although these values are smaller than unity, the increase in $u_{*} / w_{\text {ss }}$ indicates that suspended load transport becomes increasingly important resulting in increasingly offshore-directed net transport. On the basis of a large set of ripple regime net transport data, van der Werf et al. [2006] conclude that the direction of net transport is controlled by the vortex suspension parameter $P$, which is the ratio of the ripple height $\eta$ and the median grain size $D_{50}$, rather than by $u * / w_{\mathrm{ss}}$. They found net sand transport to be in the offshore direction (i.e., dominant suspended load transport) for large values of $P$ and net sand transport in the onshore direction for low values of $P$. The critical value of $P$ was found to be in the range of 70-90. The values of $P$ for experiments Mr5a63, Mr5b63 and Mr5c63 are 89, 173 and 181 , respectively. The net sand transport over ripples is thus determined by relative importance of the onshore-directed bedload and offshore-directed suspended load transport, which seems to be controlled by the vortex suspension parameter $P$.

\section{Conclusions}

[92] New measurements of the detailed, time-dependent flow and concentration field were carried out for fourteen different regular oscillatory flow conditions over rippled beds. The measurements comprise a unique data set for calculations of sand flux over mobile ripples under full-scale flow conditions. The following are the main conclusions.

[93] The velocity field above ripples is dominated by the generation and ejection of vortices on the ripple flanks around the time of flow reversal. In the case of asymmetric flows, the vortex formation on the lee side during onshore flow is much stronger than on the stoss side during offshore flow, because maximum onshore velocity is larger than maximum offshore velocity. Near-ripple flow reversal occurs at $0-0.3 T$ before the free-stream flow reversal due to the vortex formation. Near the ripple crest, $-0.25<x / \lambda<$ 0.25 , velocities can be up to 1.7 times higher than the freestream velocity because of flow acceleration over the crest and vortex ejection.

[94] Asymmetry in the free stream and the consequent asymmetry in vortex formation produces steady circulation cells with dominant offshore mean flow up the ripple lee slope and in a layer with a thickness of $1-1.5$ ripple heights 
above the ripple crest level on the stoss side of the ripple. This offshore mean flow is balanced by weaker onshore streaming up the ripple stoss slope and higher up in the flow. The time- and bed-averaged horizontal velocity profile, which is important for determining current-related sand transport, comprises an offshore near-bed streaming (for $z<\eta$ ) and an onshore drift higher up in the flow. The magnitudes of the net velocities are small, but could be potentially important for the net sand transport because of their presence in a near-bed layer with relatively high sand concentrations.

[95] The measured time-dependent concentrations under asymmetric flow conditions provide detailed information on the time- and spatially varying characteristics of the concentration field over ripples. The concentration field is dominated by the formation and ejection of the vortices on the lee slope. These vortices are responsible for three concentration peaks: one just after on-offshore flow reversal associated with the passage of a sand-laden vortex followed by two smaller peaks due to advected suspension clouds generated by vortex action at the neighboring onshore ripples. Close to the ripple crest there are also two other, even smaller peaks present associated with off-onshore flow reversal and maximum onshore flow.

[96] The time-dependent concentration measurements were combined with PIV velocity measurements to compute the instantaneous sand fluxes for one specific regular asymmetric flow condition. The temporal variation in the sand fluxes is similar to the temporal variation in the concentrations. The sand flux is dominated by an offshore flux associated with the suspended sand cloud generated by vortex shedding from the lee slope of the ripple around the time of on-offshore flow reversal. There are also onshore sand flux peaks associated with vortex shedding from the stoss slope and with maximum onshore flow velocity.

[97] The net (time-averaged) current-related and waverelated horizontal suspended sand fluxes in regular asymmetric oscillatory flow are generally negative ("offshore directed") and mostly contained in the layer $z / \eta<1.5$. As a result, the net wave-related and current-related suspended transport (vertical integrates of the horizontal sand fluxes) are also in the negative direction. The wave-related suspended transport component is larger, but the contribution of the current-related suspended sand transport cannot be neglected. In addition to the measured offshore net transport of suspended sand, there is an onshore- directed mainly bedload transport very close to the ripple surface that has not been measured directly. The total net transport (suspended load plus bedload) for this asymmetric experiment was in the offshore direction.

[98] The research has produced a data set containing detailed measurements of the transport processes over full-scale rippled beds for three different regular asymmetric oscillatory flows. To facilitate the use of these data to test and develop process-based numerical models, a database has been produced that is available on request to the corresponding author.

[99] Acknowledgments. This work has been carried out within the EU-project Sand Transport and Morphology of Offshore Sand Mining Pits (SANDPIT), contract EVK3-2001-00056. The authors are grateful to the technical staff of the University of Aberdeen (UAb) and University of Twente (UT) for assisting with the experiments, especially Rab Fraser
(UAb) and Bas van Leeuwen (UT). Chris Vincent from the University of East Anglia is acknowledged for providing the ABS and for his help with deploying the ABS and processing of the ABS data.

\section{References}

Ahmed, A. S. M., and S. Sato (2001), Investigation of bottom boundary layer dynamics of movable bed by using enhanced PIV technique, Coastal Eng., 43, 239-258.

Andersen, K. H. (1999), Ripples Beneath Surface Waves and Topics in Shell Models of Turbulence, Ph.D. thesis, Univ. of Copenhagen, Denmark.

Bosman, J. J. (1982), Concentration measurements under oscillatory motion, Tech. Rep. M1695 Part II, Delft Hydraul., Netherlands.

Bosman, J. J., E. T. J. M. van der Velden, and C. H. Hulsbergen (1987), Sand concentration measurement by transverse suction, Coastal Eng., 11, $353-370$.

Chen, Z. (1992), Sand Concentration and Sand Transport Due to Action of Waves and a Current, Ph.D. thesis, Delft Univ. of Technol., Netherlands.

Clubb, G. S. (2001), Experimental Study of Vortex Ripples in Full Scale Sinusoidal and Asymmetric Flows, Ph.D. thesis, Aberdeen Univ., UK

Davies, A. G., and P. D. Thorne (2005), Modelling and measurement of sand transport by waves in the vortex ripple regime, J. Geophys. Res., 110, C05017, doi:10.1029/2004JC002468.

Davies, A. G., and C. Villaret (1997), Oscillatory flow over rippled beds: Boundary layer structure and wave-induced Eulerian drift, in Gravity Waves in Water of Finite Depth, edited by J. N. Hunt, pp. 215-254, Comput. Mech., Billerica, Mass.

Davies, A. G., and C. Villaret (1999), Eulerian drift induced by progressive waves above rippled and very rough beds, J. Geophys. Res., 104(C1), $1465-1488$

Davies, A. G., J. S. Ribberink, A. Temperville, and J. A. Zyserman (1997), Comparisons between sand transport models and observations made in wave and current flows above plane beds, Coastal Eng., 31, $163-198$.

Davies, A. G., L. C. van Rijn, J. S. Damgaard, J. van de Graaff, and J. S. Ribberink (2002), Intercomparison of research and practical sand transport models, Coastal Eng., 46, 1-23.

Doering, J. C., and A. J. Baryla (2002), An investigation of the velocity field under regular and irregular waves over a sand beach, Coastal Eng., $44,275-300$

Doucette, J. S., and T. O'Donoghue (2006), Response of sand ripples to changes in oscillatory flow, Sedimentology, 53, 581-596.

Earnshaw, H. C., and C. A. Greated (1998), Dynamics of ripple bed vortices, Exp. Fluids, 25, 265-275.

Eidsvik, K. J. (2004), Some contributions to the uncertainty of sand transport predictions, Cont. Shelf Res., 24, 739-754.

Hansen, E. A., J. Fredsøe, and R. Deigaard (1994), Distribution of suspended sand over wave-generated ripples, J. Waterw. Port Coastal Ocean Eng., 120, 37-55.

Hoekstra, P., P. Bell, P. van Santen, N. Roode, F. Levoy, and R. Whitehouse (2004), Bedform migration and bedload transport on an intertidal shoal, Cont. Shelf Res., 24, 1249-1269.

Longuet-Higgins, M. S. (1953), Mass transport in water waves, Philos. Trans. R. Soc. London, Ser. A, 245(903), 535-581.

Malarkey, J., and A. G. Davies (2002), Discrete vortex modelling of oscillatory flows over ripples, Appl. Ocean Res., 24, 127-145.

Marin, F. (2004), Eddy viscosity and Eulerian drift over rippled beds in waves, Coastal Eng., 50, 139-159.

Nielsen, P. (1992), Coastal Bottom Boundary Layers and Sand Transport, World Sci., Hackensack, N. J.

O'Donoghue, T., and G. S. Clubb (2001), Sand ripples generated by regular oscillatory flow, Coastal Eng., 44, 101-115.

O'Donoghue, T., and S. Wright (2004), Flow tunnel measurements of velocities and sand fluxes in oscillatory sheet flow for well-sorted and graded sands, Coastal Eng., 51, 1163-1184.

Ribberink, J. S., and A. A. Al-Salem (1995), Sheet flow and suspension of sand in oscillatory boundary layers, Coastal Eng., 25, 205-225.

Sato, S. (1987), Oscillatory Boundary Flow and Sand Movement Over Ripples, Ph.D. thesis, Univ. of Tokyo, Japan.

Soulsby, R. S. (1997), Dynamics of Marine Sands, Telford, London.

Swart, D. H. (1974), Offshore Sediment Transport and Equilibrium Beach Profiles, Ph.D. thesis, Delft Univ. of Technol., Netherlands.

Thorne, P. D., A. G. Davies, and J. J. Williams (2003), Measurements of near-bed intrawave sand entrainment above vortex ripples, Geophys. Res. Lett., 30(20), 2028, doi:10.1029/2003GL018427.

Traykovski, P., A. E. Hay, J. D. Irish, and J. F. Lynch (1999), Geometry, migration, and evolution of wave orbital ripples at LEO-15, J. Geophys. Res., 104(C1), 1505-1524. 
Trowbridge, J., and O. S. Madsen (1984a), Turbulent wave boundary layers: 1. Model formulation and first-order solution, J. Geophys. Res., 89(C5), 7989-7997.

Trowbridge, J., and O. S. Madsen (1984b), Turbulent wave boundary layers: 2. Second-order theory and mass transport, J. Geophys. Res., 89(C5), 7999-8007.

Van Rijn, L. C. (1993), Principles of Sediment Transport in Rivers, Estuaries, and Coastal Seas, Aqua Publ., Amsterdam.

van der Werf, J. J. (2006), Sand Transport over Rippled Beds in Oscillatory Flow, Ph.D. thesis, Univ. of Twente, Netherlands.

van der Werf, J. J., J. S. Ribberink, T. O’Donoghue, and J. S. Doucette (2006), Modelling and measurement of sand transport process over fullscale ripples in oscillatory flow, Coastal Eng., 53, 657-673.
Villard, P. V., P. D. Osborne, and C. E. Vincent (2000), Influence of wave groups on SSC patterns over vortex ripples, Cont. Shelf Res., 20, $2391-$ 2410 .

Vincent, C. E., and D. M. Hanes (2002), The accumulation and decay of near-bed sand concentration due to waves and wave groups, Cont. Shelf Res., 22, 1987-2000.

J. S. Doucette and T. O'Donoghue, University of Aberdeen, Department of Engineering, King's College, Aberdeen, AB24 3UE, UK.

J. S. Ribberink and J. J. van der Werf, Water Engineering and Management, University of Twente, P.O. Box 217, 7500 AE Enschede, Netherlands. (j.j.vanderwerf@utwente.nl) 